\title{
Towards social life cycle assessment of mobility services: systematic literature review and the way forward
}

\author{
Katharina Gompf ${ }^{1,2}$ (D) Marzia Traverso $^{2} \cdot$ Jörg Hetterich ${ }^{1}$
}

Received: 8 March 2020 / Accepted: 30 June 2020 / Published online: 10 August 2020

(C) The Author(s) 2020

\begin{abstract}
Purpose The main purpose of this review is to describe the state of the art of social impact assessment with a focus on mobility services. Whereas the use phase plays an important role for the assessment of services in general, the evaluation of the use phase has been underrepresented in previous social life cycle assessment studies. For that reason, particular attention has been paid to indicators, which allow the assessment of social impacts during the use phase of mobility services.

Methods Continuous efforts to mitigate climate change and to improve quality of life in cities result in new mobility solutions based on collective use. This will have a huge impact on our society transforming the use of vehicles. In order to better understand the implications for cities, society and the automotive industry, it is essential to evaluate the social impact generated along a product life cycle with particular attention to the use phase. To reach the goal, a systematic literature review was carried out with a focus on social indicators that allow assessing use phase impacts of mobility services. The indicators were analysed and allocated to stakeholder groups. Based on the analysis, a core set of indicators is proposed under consideration of data availability.

Results and discussion Based on the selected search strings, 51 publications were selected for the literature review, including 579 social indicators. The analysis revealed a wide variety and diversity of indicators that are trying to measure the same aspect. The allocation to the respective stakeholder groups showed that most of the indicators (36\%) evaluate impacts regarding the stakeholder group local community. The majority of analysed indicators are of quantitative nature (63\%). Nevertheless, a clear assessment method was often missing in the respective publications. Therefore, for the core set of indicators, an assessment method is proposed for every indicator.

Conclusions The results from this study can help practitioners as well as researchers in the field of urban mobility assessment as it systematically analyses social sustainability aspects. The presented data gives an overview of various indicators that are suggested in other publications, and the proposed core set of indicators can be used to evaluate different mobility services in further research.
\end{abstract}

Keywords Mobility services $\cdot$ Social life cycle assessment $\cdot$ S-LCA $\cdot$ Use phase $\cdot$ Social sustainability indicators $\cdot$ Systematic literature review

\section{Introduction}

The automotive industry will have to navigate through a number of difficult challenges in the upcoming years. With advancing climate change, the pressure to reduce $\mathrm{CO}_{2}$ emissions

Communicated by Matthias Finkbeiner

Katharina Gompf

Katharina.Gompf@bmw.de

BMW Group, Knorrstraße 147, 80788 Munich, Germany

2 Institute of Sustainability in Civil Engineering, RWTH Aachen University, Aachen, Germany is rising. Due to urbanisation and growing population, cities around the world are fighting with rising traffic, declining air quality and limited space availability (Gross 2019). Stricter regulations regarding emissions, restrictions for private car use in cities and limited parking options are only some of the consequences. As a result, private car ownership becomes less attractive in urban areas. In addition, greater health awareness and concern for the environment support this movement away from the personal car (Morrison and Beer 2017). Considering that more than $50 \%$ of the world's population live in cities (United Nations 2011), the automotive industry is seeking alternative business models to address the challenges that result from urbanisation. Numerous new passenger transportation options, collectively called mobility services, 
have been developed over the past 15 years. These mobility services have been identified as one possible option to address the current challenges (Gould et al. 2015). Mobility services are user-centric and responsive to the needs, habits and preferences of travellers and society. They enable users to have access to transportation services for short- and long-term periods and on demand. Mobility services often blur the lines between public transportation and private ownership (Kamargianni et al. 2016). Car-sharing, ride-hailing, ridesharing, microtransit and bike-sharing are some examples of mobility services currently being developed. Each has its own underlying service characteristics and business model (Spulber et al. 2016). Hietanen (2014) gave one of the first comprehensive definitions of mobility as a service (MaaS). He describes MaaS as a mobility distribution model that delivers users' transport needs through a single interface of a service provider. It combines different transport modes to offer a tailored mobility package. Burrows et al. (2015) defines MaaS as a new way to provide transport, which facilitates the users to get from A to B by combining available mobility options and presenting them in a completely integrated manner. The most cited definition for MaaS, however, is from the European MaaS Alliance, which defines the concept as "the integration of various forms of transport services into a single mobility service accessible on demand" (Durand et al. 2018). Despite the novelty of the MaaS concept and the challenge to describe its nature, a set of core characteristics can be derived from literature review, such as personalisation, customisation, tariff options, real-time information, trip planning, booking and ticketing as well as employed technologies like GPS, Eticket and E-payment (Jittrapirom et al. 2017). According to these definitions, the unifying feature of any MaaS implementation is the integration of multiple mobility services. This means that car-sharing, bike-sharing, ride-hailing, etc., are not themselves MaaS without meaningful multi-modal integration. Car manufacturers (such as Daimler, BMW or Volkswagen) identified mobility services and MaaS as additional business opportunity, especially in urban areas, and are involved in car-sharing or ride-hailing operations. The years 2018 and 2019 were full of merges, acquisitions and new players in the field of mobility services. In the past 3 years, close to 1000 cities have added car-sharing alone, which is an increase of $47 \%$ (Philipps 2019). Further, scooter and bikesharing services are growing in numbers. Two types of scooter-sharing systems can be distinguished: standing electric and moped-style scooters. In Taiwan, for example, the number of moped-style electric scooters increased ten times from 2016 to 2018, mainly due to battery-sharing systems (Pham et al. 2019). The standing electric scooters, e.g. operated by Bird or Lime, can be found in over 100 metropolitan areas around the globe. The major standing scooter-sharing service in the USA, Bird, launched its service in over 50 cities across Europe in 2019 (Shaheen et al. 2020). However, not only scooter- and car-sharing services are growing rapidly, also bike-sharing is on the rise. According to MoonMiklaucic et al. (2019), approximately 95\% of the 1600 bike-sharing operators in 2017 were launched since 2007, with more than 200 in 2017 alone.

As different mobility services are growing in cities around the world, the question that automatically arises is whether mobility services can lead to more sustainable transportation options, thereby improving quality of life in cities. In order to answer this question, it is important to analyse sustainability impacts of these mobility services in a systematic way, considering all three dimensions of sustainability: economic, ecologic and social. This is essential to avoid burden shifting; for example, an improvement regarding ecological impacts could lead to negative social impacts. Life cycle-based methodologies have been developed over time for this purpose (Curran 1996; ISO 14040 2006; Finkbeiner et al. 2010). Although a lot of research has been done concerning economic and environmental assessment, a standardised approach for social life cycle assessment (S-LCA) has yet to be agreed on (e.g. DuboisIorgulescu et al. 2016). Different S-LCA indicators and impact assessment methods have been applied and tested in a number of case studies (Di Cesare et al. 2018). The use phase plays an important role for the assessment of mobility services; for example, shared cars are used in a very different way than conventional cars in private ownership. The evaluation of the use phase, however, has been underrepresented in previous S-LCA case studies (Petti et al. 2016). Therefore, it is important to focus on use phase social impacts, not only to have a consistent assessment along all three dimensions of sustainability and to avoid burden shifting but also to be able to measure positive impacts. The assessment of positive impacts is crucial when analysing the impacts of mobility services; for example, an improved access to mobility, a higher degree of security or affordability should also be captured. For a deeper understanding of the study and more background information, the methodology of social life cycle assessment is introduced (Section 1.1) before analysing mobility services in the context of S-LCA and use phase assessment (Section 1.2).

\subsection{Social life cycle assessment, a methodological description}

S-LCA is a rather new approach compared to life cycle assessment (LCA) and life cycle costing (LCC), and it aims to address the social impacts of goods and services along their life cycle. The starting point is the established methodology of LCA according to the ISO 14040 (2006). About 26 years ago, a "social welfare impact category" was proposed in the SETAC Workshop Report (1993): "A Conceptual Framework for Life Cycle Impact Assessment". This started the discussion on how to deal with social and socio-economic 
criteria in assessing a product along its life cycle. The main topic of discussion during the second half of the 1990s was to what extent a life cycle assessment of a product or a service taking into account social criteria is different from LCA. Just like LCA, it was proposed to conduct S-LCA in line with ISO 14040 (2006). A crucial differentiation point for S-LCA is that impact categories may be assessed using different indicators depending on the stakeholder group under consideration.

An important achievement in the ongoing development of S-LCA was the issuing of the UNEP/SETAC S-LCA Guidelines in 2009. According to the UNEP/SETAC Guidelines 2009 "a social and socio-economic Life Cycle Assessment (S-LCA) is a social impact (and potential impact) assessment technique that aims to assess the social and socioeconomic aspects of products and their potential positive and negative impacts along their life cycle" (UNEP/SETAC 2009). The UNEP/SETAC Guidelines (also referred to as the Guidelines hereafter) provide a good framework on how S-LCA should be conducted. The framework includes five stakeholder categories as well as six impact categories with 31 subcategories, an inventory analysis and, finally, the impact assessment. The categories identified are the following: human rights, working conditions, health and safety, cultural heritage, governance and socio-economic repercussions. The five stakeholder categories are comprised of workers, local community, society, value chain actors and consumers. The five stakeholder categories have eight, eleven, three, four and five subcategories, respectively. These subcategories are characterised with the help of more than 100 inventory indicators and published in a separate document: "The methodological sheets for subcategories in social life cycle assessment" (UNEP/SETAC 2013). However, these indicators and the corresponding reference to required raw data are only suggestions. The user can select relevant indicators and data sources, e.g. generic or specific data sources.

After the publication of the Guidelines, many S-LCAs were conducted according to the given framework (Petti et al. 2016). Though, among other shortcomings, no clear methodology for the impact assessment is given in the Guidelines: "In the impact assessment step of an S-LCA the distribution and share of positive and negative impacts is important to consider. How this should be done is an issue of further research and testing in case studies" (UNEP/SETAC 2009). This is the reason why the S-LCA research community have used various methods for the impact assessment (Russo Garrido et al. 2016). In general, the impact assessment methods can be classified into two broad categories: the performance reference point methods (type I) and the impact pathway methods (type II), as shown in Fig. 1 (Parent et al. 2010; Chhipi-Shrestha et al. 2014).

Performance reference point methods assess social impacts using performance reference points based on minimum performance levels (Franze and Ciroth 2011; Ramirez et al.
2014). For these kinds of minimum performance levels, internationally accepted standards are used such as International Labour Organization (ILO) Conventions, the ISO 26000 Guidelines and OECD Guidelines for Multinational Enterprises. Colour-coding, scoring and weighting systems are used for aggregating the inventory indicator data to impact categories (e.g. human rights). These approaches do not use cause-effect chains because the authors are of the opinion that "cause-effect relationships are not simple enough or not known with enough precision to allow quantitative causeeffect modelling" (UNEP/SETAC 2009). These approaches are included as type I impact assessment by UNEP/SETAC Guidelines.

Impact pathway methods, on the other hand, assess the social impacts by means of impact pathways as characterisation models. Midpoint indicators and/or endpoint indicators are used, comparable to LCA. These methods are based on social effects and mostly on quantitative indicators. Unlike performance reference point methods, for these methods, cause-effect chains are used (Weidema 2018). They are included in type II impact assessment by the UNEP/SETAC Guidelines. Figure 1 shows both performance reference point-based methods (type I) and impact pathway-based methods (type II).

Another important document is the Handbook for Product Social Impact Assessment (PSIA), first published in 2014 and last updated in 2018. The PSIA is a more practical approach, developed mostly by industry leaders but started from the main scientific literature. Those were analysed and compared against the company strategy to identify key social topics and stakeholder categories. The PSIA refers to four main stakeholder categories: workers, small-scale entrepreneurs, local communities and users. The PSIA defines social topics for every stakeholder group. Social topics are social areas related to stakeholder groups such as working hours, community engagement or child labour. For every social topic, a performance indicator is defined. As the name suggests, performance indicators measure the performance of each social topic, for example the number of working hours per week or minimum wage paid. The performance indicators can be quantitative or qualitative. Two different types of metrics can be used: either full quantification of all data or a reference-scale approach. For the reference-scale approach, a score ranging from -2 to +2 is proposed. This allows to measure positive as well as negative impacts. The impact assessment method described in the PSIA suggests aggregation of performance indicators into social topic scores, stakeholder scores and a total score (Fontes et al. 2016; Goedkoop et al. 2018).

The presented social topics in the PSIA are often overlapping with the subcategories of the Guidelines. The respective indicators, however, differ greatly and target different issues, as can be seen in Table 1. For example, regarding the 
Fig. 1 Performance reference point-based methods (type I) and impact pathway-based methods (type II)
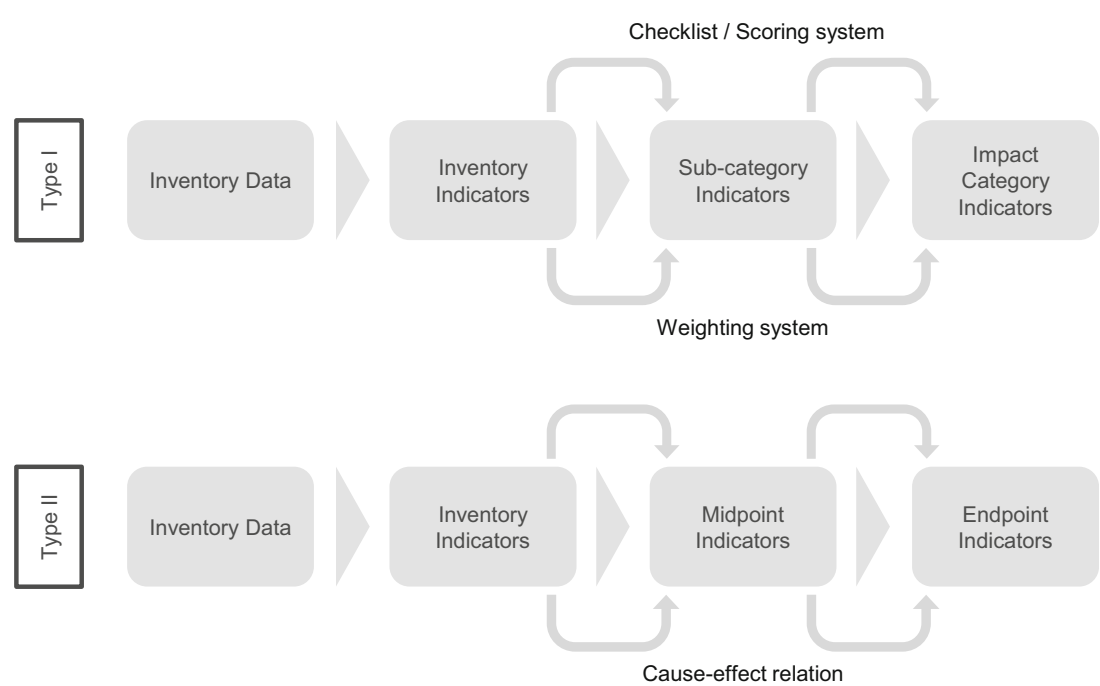

stakeholder group local community, both the Guidelines and the PSIA suggest indicators to assess impacts on local employment. Nevertheless, the Guidelines, in addition, include indicators that measure access to material and immaterial resources, which are missing in the PSIA. On the other hand, the PSIA includes indicators regarding skill development, which is not included in the Guidelines. As the stakeholder group consumers, respectively users, is of importance for use phase assessment of mobility services, a focus lies on this stakeholder group. According to the Guidelines, the stakeholder group consumer covers "endconsumers as well as the consumers who are part of each step of the supply chain" (UNEP/SETAC 2009). The PSIA, however, is referring to the term 'user' and makes a distinction between products developed for consumers and products developed for workers, which can be seen as professional users. In that way, a distinction between primary, secondary and passive users is made. In the example of a public bus transport, the differentiation of these three kinds of users is explained. A person taking the bus from $\mathrm{A}$ to $\mathrm{B}$ is a primary user. However, the driver or the person who cleans the bus can be seen as a secondary user. Further, people who do not use, drive or maintain the bus may also be impacted, for example by exposure to potential noise or congestion. This last group of stakeholders is referred to as passive users. Therefore, the definition by PSIA is broader as it includes consumers, workers and passive users (Goedkoop et al. 2018). When analysing the stakeholder group consumers (Guidelines) and users (PSIA) in detail, some similarities as well as major differences can be found. It is notable that in the Guidelines and in the PSIA, 'privacy' is one of the topics that overlap. The suggested indicators, however, vary to a great extent. Whereas the Guidelines suggest indicators focusing on country rankings or strength of policies regarding privacy, the PSIA lies the focus on company implementations concerning privacy. The Guidelines, in addition, include the number of consumer complaints or complaints by regulatory bodies related to privacy as quantitative indicator, whereas the PSIA includes scale-based indicators assessing the company's performance, without stating any quantitative indicators. Other categories show similar variations. 'Health and safety' are combined into one category in the Guidelines, whereas the PSIA separates this category into two social topics. The Guidelines include the subcategories 'Feedback mechanism', 'Transparency' and 'End-of-life responsibility', which are missing in the PSIA. The PSIA, though, includes 'Responsible communication', 'Inclusiveness' and 'Effectiveness and comfort', which are not included in the Guidelines. Consequently, the stated indicators for those subcategories and social topics are not overlapping and assess different aspects. In Table 2, a full list of suggested indicators is presented according to the Guidelines and the PSIA, which reveals the different indicators in detail. The major differences in the presented categories and indicators underline that no standardised approach has been defined for category and indicator selection and highlights the necessity of further research regarding the selection of categories and indicators for the assessment of mobility services.

\subsection{Mobility services in the context of S-LCA and use phase assessment}

Social welfare is considered one of the main development goals of modern society. Understanding and assessing what could improve or undermine well-being is a key element in public policies. In the last years, increasing concern about urban mobility can be observed through scientific and nonscientific literature. Sustainable urban mobility has become one of the main challenges. According to Gould et al. (2015), mobility services have the potential to improve quality of life in cities by reducing the use of private cars and encouraging the diffusion of electric vehicles within cities. Further, mobility services lead to increased mobility options that may result in time saved by users or higher comfort due to, for example, closer pick-up locations (Karlsson et al. 2019). 
Table 1 Subcategories and social topics as presented in the Guidelines and in the PSIA

\begin{tabular}{l} 
UNEP/SETAC Guidelines \\
\hline Local community \\
Delocalisation and migration \\
Community engagement \\
Cultural heritage \\
Respect of indigenous rights \\
Local employment \\
Access to immaterial resources \\
Access to material resources \\
Safe and healthy living conditions \\
Secure living conditions \\
Consumer \\
Health and safety \\
Feedback mechanism \\
Privacy \\
Transparency \\
End-of-life responsibility \\
Value chain actors \\
Fair competition \\
Respect of intellectual property rights \\
Promoting social responsibility \\
Worker \\
Freedom of association and collective bargaining \\
Fhild labour \\
Health and sary \\
Social benefit/social security \\
Foork
\end{tabular}

Handbook for Product Social Impact Assessment (PSIA)

Local community

Community engagement

Employment and skill development

Access to tangible resources

Health and safety

User

Health

Safety

Privacy

Responsible communication

Inclusiveness

Effectiveness and comfort

Worker

Freedom of association and collective bargaining

Child labour

Remuneration

Work-life balance

Forced labour

Discrimination

Health and safety

Small-scale entrepreneurs

Fair trading relationships

Land rights

Women's empowerment

Child labour

Health and safety

Access to services and inputs

Meeting basic needs

\footnotetext{
Society

Public commitment to sustainability issues

Prevention and mitigation of conflicts

Contribution to economic development

Corruption

Technology development
}

Ride-hailing services, like Uber or Lyft, claim higher safety for their users compared to traditional taxi services due to online tracking and user review options. On the other hand, rising numbers of accidents with shared electric scooters suggest higher health and safety risks for its users (Blomberg et al. 2019).
In the automotive industry, strict health and safety requirements exist, which are monitored and controlled with respective simulations and crash tests. Interior emissions, for example, are tracked and measured to ensure drivers' and passengers' health, not to mention emissions from the internal combustion engine. However, mobility services take social 
Table 2 Full list of suggested indicators for the stakeholder groups consumer (Guidelines) and user (PSIA)

\section{UNEP/SETAC Guidelines}

\section{Consumer}

Health and Safety

Quality of or number of information/signs on product health and safety (quantitative, semi-quantitative)

Presence of consumer complaints (at national, sectorial or organisational level) (quantitative, semi-quantitative)

Total number of incidents of non-compliance with regulations and voluntary codes concerning health and safety impacts of products and services and type of outcomes (quantitative, semi-quantitative, qualitative)

Number of consumer complaints (quantitative/semi-quantitative)

Presence of management measures to assess consumer health and safety (qualitative)

Quality of labels of health and safety requirements (qualitative/semi-quantitative)
Handbook for Product Social Impact Assessment (PSIA)

User

Health

There is solid science-based evidence that normal use of the product enables and significantly contributes to an improved health condition for user in comparison to alternative solutions (scale-based)

The company has a dossier or other evidence that shows how the product or service has been designed to create a maximum contribution to health of the user and, if applicable, encourage a healthy lifestyle (scale-based)

The product or service conforms to all national requirements in the markets where the product is offered (scale-based)

The normal use of the product has negative health impacts on the long run (scale-based)

Any use of the product has direct negative health impacts on short and long terms (scale-based)

The company or facility has continuous user-facing education in place to raise awareness and educate users on health-related issues associated with the product (scale-based)

\section{Safety}

There is solid science-based evidence that normal use of the product is safer for active or passive users than alternative solutions and that the product or service eliminates a risk in common products and services used for the same purpose (scale-based)

The company has a dossier or other evidence that shows how the product or service has been designed to create maximum safety for active and passive users (scale-based)

The product conforms to all national requirements regarding product safety (scale-based)

The normal use of the product or services can cause higher risks compared to alternative solutions (scale-based)

Any use of the product can be regarded as unsafe (scale-based)

The company has user-facing programmes in place to raise awareness and educate users on safety risks associated with the product (scale-based)
Feedback mechanism

Presence of feedback mechanisms (e.g. after sale services) (by organisation or sector/country) (quantitative, qualitative and semi-quantitative)

Number of consumer complaints at the sector level (quantitative, qualitative and semi-quantitative)

Presence of a mechanism for customers to provide feedback (quantitative, qualitative and semi-quantitative)

Management measures to improve feedback mechanisms (quantitative, qualitative and semi-quantitative)

Practices related to customer satisfaction, including results of surveys measuring customer satisfaction (quantitative, qualitative and semi-quantitative)

\section{Privacy}

Country ranking related to regulations on data-sharing (semi-quantitative)

Country ranking related to strength of laws protecting privacy against organisations and government (semi-quantitative)

Country ranking related to the strength of regulatory powers to investigate privacy-related complaints (semi-quantitative)

Strength of internal management system to protect consumer privacy, in general (qualitative or semi-quantitative)

Number of consumer complaints related to breach of privacy or loss of data within the last year (quantitative)

Number of complaints by regulatory bodies related to breach of consumer privacy or loss of data within the last year (quantitative)

\section{Privacy}

The company has a policy to protect user data privacy (scale-based)

The company shares or sells one or more types of sensitive private data without user consent and without transparency that it does so (scale-based) The company uses and processes one or more types of sensitive private data without user consent and without giving users access to the content of that data and the purposes for which it is used (scale-based)

The way private data are used complies with the local law in the jurisdiction where the product or service is offered (scale-based)

If no regulation exists, the company or facility does not collect, process and share sensitive data, or the company does not store, (re)sell or use any privacy-related data (scale-based)

The company has a PDCA process in place to exceed the minimum legal standard and to actively rise above the requirements (scale-based)

The company has established a grievance mechanism (scale-based) 
Table 2 (continued)

Transparency

Presence of a law or norm regarding transparency (by country and/or sector) (semi-quantitative/qualitative)

Sector transparency rating; number of organisations by sector which published a sustainability report (quantitative/semi-quantitative/qualitative)

Non-compliance with regulations regarding transparency (semi-quantitative/qualitative)

Consumer complaints regarding transparency (semi-quantitative/qualitative)

Publication of a sustainability report (semi-quantitative/qualitative)

Quality and comprehensiveness of the information available in the sustainability report or other documents regarding the social and environmental performance of the organisation (qualitative)

Communication of the results of social and environmental life cycle impact assessment (semi-quantitative/qualitative)

Certification/label the organisation obtained for the product/site (semi-quantitative/qualitative)

Company rating in sustainability indices (Dow Jones Sustainability Index, FTSE4Good, ESI, HSBC, Corporate Sustainability Index, etc.) (semi-quantitative/qualitative)

End-of-life responsibility

Strength of national legislation covering product disposal and recycling (semi-quantitative)

Do internal management systems ensure that clear information is provided to consumers on end-of-life options (if applicable)? (Semi-quantitative)

Annual incidents of non-compliance with regulatory labelling requirements (quantitative)
The company does not get any revenue from (re)selling personal data to other entities (scale-based)

The company's commitments are publicly available (scale-based)

Responsible communication

The product is labelled according to the regulations in the country of sale (scale-based)

The company has a responsible communication policy (scale-based)

A grievance mechanism is in place to enable feedback from users (scale-based)

No incidents of misleading communication have been found in the last year (scale-based)

The company adheres to commonly accepted principles (scale-based)

The communication by the company and its resellers is deliberately designed to avoid misleading claims (scale-based)

Claims made in marketing and product documentation that the product or its use supports a more sustainable lifestyle are all backed up with science-based evidence, 3rd-party market research or research following international and national standards. The evidence is publicly available and easy to access for all users and potential users (scale-based)

A mechanism in place to engage in dialogues with users and consumers (scale-based)

Inclusiveness

The company has a policy to design and market a product or service with an objective to improve affordability and accessibility (scale-based)

The solution offered by the company is designed in such a way that it does not hinder or improve the access and use of an essential product or service by vulnerable groups (scale-based)

The solution offered by the company is designed and marketed to give access to essential products and services to all users/to the most vulnerable groups/an income class that would not otherwise be able to afford it (scale-based)

The company offers products and services at lower cost than the traditional solutions (scale-based)

The solution offered by the company is not accessible or useable by vulnerable people, even though these groups could really benefit from having access (scale-based)

Effectiveness and comfort

The product is best in class in terms of effectiveness, efficiency or comfort (scale-based)

The product or service solution performs average in terms of effectiveness or comfort or does not affect it compared to standard solutions (scale-based)

The product or service solution makes users less effective or comfortable compared to standard solutions (scale-based)

The product or service solution contributes to ineffectiveness or discomfort (scale-based)

The company has a dossier or other evidence that shows how the product or service has been designed to maximise effectiveness, efficiency or comfort (scale-based)

There is science-based evidence or 3rd-party market research that the offered product and service solution makes the user or use much more effective or comfortable compared to standard solutions (scale-based) 
impacts to a new level, as the stated examples emphasise. To be able to better understand the implications of mobility services and to improve quality of life in cities, it is therefore essential to evaluate the social impacts in a systematic way, including all related stakeholder groups. In doing so, it is necessary to be able to measure potential positive impacts, for example time saved or increased comfort.

Although the UNEP/SETAC Guidelines as well as the PSIA are applicable for both products and services, most applications focus on products. Petti et al. (2016) systematically investigated S-LCA case studies that have been conducted according to the UNEP/SETAC Guidelines between 2010 and 2015. Among the analysed case studies, $32 \%$ used system boundaries from 'cradle to grave' and 3\% from 'gate to grave', making it only $35 \%$ of the studies that consider use phase impacts. In addition, only $7 \%$ of the studies conducted according to the UNEP/SETAC Guidelines consider the stakeholder group 'consumers'. Zanchi et al. (2018) analysed S-LCA applications in the automotive sector. Out of the thirteen identified S-LCA applications in the automotive sector, only four considered the stakeholder group 'local community' and none of the analysed S-LCA applications considered the stakeholder group consumers. Tarne et al. (2017) focused on LCSA in the automotive industry and thereby analysed S-LCA studies. A comparatively low maturity of S-LCA in the automotive sector was identified. Whereas most of the applications in the automotive sector focus on materials and automotive parts, none of the analysed studies applied the S-LCA framework to mobility services (Zanchi et al. 2018). Consequently, the question is whether the suggested indicators in the Guidelines and the PSIA are adequate for the assessment of mobility services, especially the ones recommended for the stakeholder group consumers and users (Table 2).

Indicators help to transfer complex issues into understandable figures and allow to monitor goals as well as to measure targets. They can establish a common language to communicate impacts and support in decision-making. The choice of indicators is therefore essential as it directly affects management and decision-making. Nevertheless, choosing the right indicators is challenging, as hundreds of indicator systems are available, typically each developed for a specific purpose (Huovila et al. 2019). Considerable efforts have been made to develop indicators that can be used to assess urban mobility, often in the context of measuring the sustainability of a city as a whole. However, these indicators do not fulfil the specific requirements to measure the impact of mobility services. For this reason, a systematic literature review was carried out with a focus on social indicators that allow the assessment of the use phase impacts of mobility services. The indicators were analysed and allocated to stakeholder groups in order to identify hotspots as well as weaknesses. Finally, the indicators are compared to the ones suggested in the Guidelines and the PSIA in order to lead the way towards a comprehensive and inclusive set of indicators for the assessment of mobility services.

\section{Methods}

For the systematic literature review, Web of Science, ScienceDirect and Springer Link were used. As search strings, multiple notations of 'life cycle assessment', 'S-LCA', 'sustainable urban mobility', 'social sustainability' or 'sustainable urban transportation' were used in combination with the following keywords:

- (LCA OR 'Life Cycle Assessment' OR 'Life-cycle assessment' OR 'Life-cycle-assessment') AND 'Mobility' AND 'Mobility Service*'

- (LCA OR 'Life Cycle Assessment' OR 'Life-cycle assessment' OR 'Life-cycle-assessment') AND 'Sustainable City'

- (LCA OR 'Life Cycle Assessment' OR 'Life-cycle assessment' OR 'Life-cycle-assessment') AND 'City' AND 'Indicator*'

- ('Social life cycle assessment' OR 'Social LCA' OR 'S-LCA') AND 'Mobility' AND 'Mobility Service*'

- ('Social life cycle assessment' OR 'Social LCA' OR 'S-LCA') AND 'Sustainable City'

- ('Social life cycle assessment' OR 'Social LCA' OR 'S-LCA') AND 'City' AND 'Indicator*'

- ('Sustainable urban mobility') AND ('Social indicator*')

- ('Social sustainability') AND ('transportation systems')

- ('Sustainable urban transportation') AND ('social indicator*')

Excluded from the results were all secondary studies, duplicate studies, primary studies not written in English or grey literature. Only articles from peer-reviewed journals written in English were selected, published between 2011 and 2019. The selection process can be described in four phases. In the first phase, only publications that include social indicators were filtered. In the second phase, the social indicators were categorised according to associated stakeholder groups and clustered in an analytical grid. The selection of the stakeholder groups was done in accordance with the Guidelines (UNEP/SETAC 2009) and the corresponding methodological sheets (UNEP/SETAC 2013): workers, local community, society, value chain actors and consumers. While identifying the stakeholder group, it was also analysed whether the indicators are of quantitative (q), semi-quantitative (s) or qualitative/ descriptive (d) nature. In some cases, the indicator type was not stated and was therefore not identified (n.i.). In the third phase, indicators were selected based on their relevance for mobility services. For this purpose, 'relevance' was defined as suggested by Laprise et al. (2015): the indicator reflects the 
performance in relation to a given criterion. In this case, the criterion is sustainable urban mobility. This allows to select, for example, an indicator assessing impacts on space occupancy and, at the same time, allows to not select, for example, an indicator assessing the number of beds of medical institutions per capita, as this does not measure the performance of a mobility service in relation to sustainable urban mobility. In a subsequent step, measurability as well as data availability were examined. For the selection based on measurability, the following criteria were fixed: (1) The indicator is already being measured or can be measured with little extra effort, (2) the measurement will show change over a year and (3) the measurement can be compared with other mobility services (Kunstler et al. 2016). In the fourth phase, the selected indicators were supplemented by missing aspects presented in the Guidelines and the PSIA. In Fig. 2, the four phases are illustrated. After the systematic literature research in the stated databases and identification of all publications that include relevant social indicators, a total of 51 papers were selected, as shown in Table 3.

\section{Results and discussion}

Based on the search strings and the focus on urban mobility, the selected publications focus on sustainability assessment of cities $(47 \%)$, transportation systems $(21 \%)$, neighbourhoods $(16 \%)$ or infrastructure/building projects $(8 \%)$. Only a few studies matched the search criteria with a different focus, for

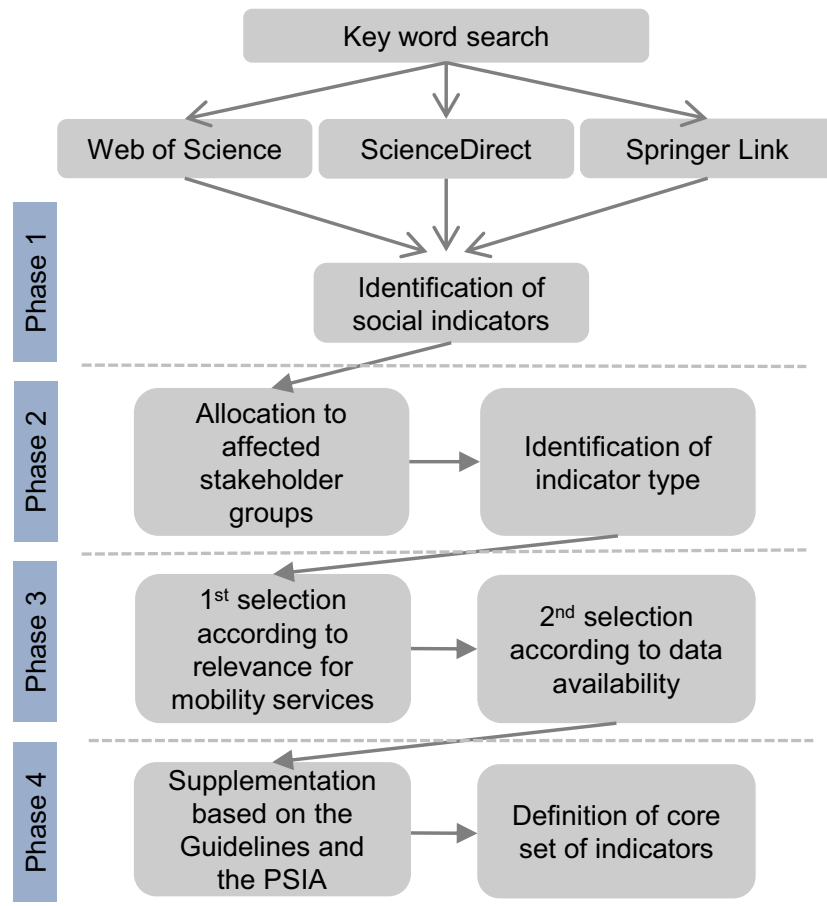

Fig. 2 Method for the definition of set of indicators to assess social sustainability of mobility services example social aspects in the mining sector or domestic water reuse ( $8 \%$ others) (see Fig. 3).

In total, 579 social indicators were identified (phase 1). The allocation of the indicators to associated stakeholder groups and the identification of the indicator type (phase 2) demonstrate that out of the identified indicators, 209 (36\%) assess social impacts that affect the stakeholder group local community. One hundred seventy (29\%) of the indicators are societal or institutional, whereas $159(28 \%)$ target the stakeholder group 'consumer'. Thirty-seven $(6 \%)$ of the analysed indicators assess social impacts related to the stakeholder group 'worker' and only 4 (1\%) 'value chain actors', which can be seen in Fig. 4.

The fact that the stakeholder group worker is underrepresented might be unexpected. This result differs from other SLCA case study reviews where $32 \%$ considered workers (Petti et al. 2016). However, this outcome can be explained by the focus of this literature review on the assessment of use phase impacts. Consequently, indicators assessing impacts regarding the local community, society or consumers become more prominent, whereas workers and value chain actors get less attention.

Out of the total amount of 579 social indicators, $365(63 \%)$ are quantitative, whereas $74(13 \%)$ are semi-quantitative. Sixty-one indicators $(10 \%)$ are of qualitative or descriptive nature, and for 79 (14\%), the assessment method was not stated and therefore the type of indicator could not be identified (see Fig. 5). An overview of the results of phase 2 can be seen in Table 4.

In the subsequent step, for each stakeholder group, all indicators that fulfil the defined precondition regarding relevance for the assessment of mobility services were filtered and grouped into categories. For every indicator, data availability was analysed. For this purpose, different possible data sources were examined, including geographic information systems, publicly available data from mobility service providers as well as the social hotspots database (SHDB) and data collection possibilities described by the methodological sheets (UNEP/SETAC 2013). For the analysis of data availability, three classifications were used in line with Litman and Burwell (2006): (1) limited, may require special data collection; (2) often available but not standardised; and (3) usually available in standardised form. This is necessary, as some indicators require data that may be difficult to obtain or evaluate. The costs of data collection and ease of use should be taken into consideration when selecting indicators. Nevertheless, indicators should not be selected only based on data availability, as important aspects may be missed (Science for Environment Policy 2018).

The analysis of the filtered and grouped indicators (phase 3, see Fig. 2) reveals that most of the indicators of the stakeholder group local community assess impacts on public space (29\%). Many different indicators can be found in this 
Table 3 Summary table of the analysed publications

\begin{tabular}{|c|c|c|c|}
\hline Author & Year & Focus area & Title \\
\hline Ameen and Mourshed & 2019 & Cities & $\begin{array}{l}\text { Urban sustainability assessment framework development: the ranking and weighting of Iraqi } \\
\text { indicators using analytic hierarchy process (AHP) }\end{array}$ \\
\hline Anisurrahman and Alshuwaikhat & 2019 & Cities & Determining sustainability assessment indicators for the Holy City of Makkah, Saudi Arabia \\
\hline Aparcana and Salhofer & 2013 & Others & $\begin{array}{l}\text { Development of a social impact assessment methodology for recycling systems in } \\
\text { low-income countries }\end{array}$ \\
\hline Azami et al. & 2015 & Cities & Recognition of urban unsustainability in Iran \\
\hline Bandeira et al. & 2018 & Transportation systems & $\begin{array}{l}\text { A fuzzy multi-criteria model for evaluating sustainable urban freight transportation opera- } \\
\text { tions }\end{array}$ \\
\hline Bui et al. & 2017 & Others & $\begin{array}{l}\text { Proposal of an indicator-based sustainability assessment framework for the mining sector of } \\
\text { APEC economies }\end{array}$ \\
\hline de Oliveira Cavalcanti et al. & 2017 & Cities & Sustainability of urban mobility projects in the Curitiba metropolitan region \\
\hline Choon et al. & 2011 & Cities & A sustainable city index for Malaysia \\
\hline Ding et al. & 2015 & Cities & An inclusive model for assessing the sustainability of cities in developing countries \\
\hline Dizdaroglu and Yigitcanlar & 2014 & Neighbourhoods & $\begin{array}{l}\text { A parcel-scale assessment tool to measure sustainability through urban ecosystem compo- } \\
\text { nents: the MUSIX model }\end{array}$ \\
\hline Dur et al. & 2014 & Neighbourhoods & $\begin{array}{l}\text { A spatial-indexing model for measuring neighbourhood-level land-use and transport inte- } \\
\text { gration }\end{array}$ \\
\hline Feleki et al. & 2018 & Cities & $\begin{array}{l}\text { Characterisation of sustainability in urban areas: an analysis of assessment tools with } \\
\text { emphasis on European cities }\end{array}$ \\
\hline Fouda and Elkhazendar & 2019 & Cities & $\begin{array}{l}\text { A criterion for modelling the 'live-and-work' city index using sustainable development } \\
\text { indicators }\end{array}$ \\
\hline Gonzalez-Garcia et al. & 2018 & Cities & $\begin{array}{l}\text { Assessing the sustainability of Spanish cities considering environmental and socio-economic } \\
\text { indicators }\end{array}$ \\
\hline Haghshenas and Vaziri & 2012 & Cities & Urban sustainable transportation indicators for global comparison \\
\hline Harijani et al. & 2017 & Others & A multi-objective model for sustainable recycling of municipal solid waste \\
\hline Hély and Antoni & 2019 & Cities & $\begin{array}{l}\text { Combining indicators for decision making in planning issues: a theoretical approach to } \\
\text { perform sustainability assessment }\end{array}$ \\
\hline Jasti and Ram & 2018 & Transportation systems & $\begin{array}{l}\text { Integrated performance assessment and service level benchmarking of urban bus system } \\
\text { using fuzzy logic }\end{array}$ \\
\hline Kawakubo et al. & 2018 & Cities & Sustainability assessment of cities: SDGs and GHG emissions \\
\hline Laprise et al. & 2018 & Neighbourhoods & $\begin{array}{l}\text { An operational monitoring tool facilitating the transformation of urban brownfields into } \\
\text { sustainable neighbourhoods }\end{array}$ \\
\hline $\mathrm{Li}$ and $\mathrm{Li}$ & 2017 & Cities & $\begin{array}{l}\text { Assessing urban sustainability using a multi-scale, theme-based indicator framework: a case } \\
\text { study of the Yangtze River Delta region, China }\end{array}$ \\
\hline Lu et al. & 2017 & Neighbourhoods & $\begin{array}{l}\text { Measuring sustainability at the community level: an overview of China's indicator system on } \\
\text { National Demonstration Sustainable Communities }\end{array}$ \\
\hline Lu et al. & 2016 & Cities & Sustainability investigation of resource-based cities in north-eastern China \\
\hline Mansourianfar and Haghshenas & 2018 & Infrastructure or building projects & $\begin{array}{l}\text { Micro-scale sustainability assessment of infrastructure projects on urban transportation } \\
\text { systems: case study of Azadi district, Isfahan, Iran }\end{array}$ \\
\hline Mapar et al. & 2017 & Cities & $\begin{array}{l}\text { Sustainability indicators for municipalities of megacities: integrating health, safety and } \\
\text { environmental performance }\end{array}$ \\
\hline Miller et al. & 2016 & Transportation systems & Analysing the sustainability performance of public transit \\
\hline Onat et al. & 2014 & Transportation systems & Towards life cycle sustainability assessment of alternative passenger vehicles \\
\hline Opher et al. & 2018 & Others & $\begin{array}{l}\text { Comparative life cycle sustainability assessment of urban water reuse at various } \\
\text { centralization scales }\end{array}$ \\
\hline Oregi et al. & 2016 & Neighbourhoods & $\begin{array}{l}\text { Sustainability assessment of three districts in the city of Donostia through the NEST } \\
\text { simulation tool }\end{array}$ \\
\hline Oses et al. & 2017 & Transportation systems & $\begin{array}{l}\text { A multidisciplinary sustainability index to assess transport in urban areas: a case study of } \\
\text { Donostia-San Sebastian, Spain }\end{array}$ \\
\hline Oswald Beiler and Mohammed & 2016 & Transportation systems & $\begin{array}{l}\text { Exploring transportation equity: development and application of a transportation justice } \\
\text { framework }\end{array}$ \\
\hline Papoutsis et al. & 2018 & Transportation systems & $\begin{array}{l}\text { Sustainability assessment of retail logistics solutions using external costs analysis: a } \\
\text { case-study for the city of Antwerp }\end{array}$ \\
\hline Phillis et al. & 2017 & Cities & Urban sustainability assessment and ranking of cities \\
\hline Rajak et al. & 2016 & Transportation systems & Sustainable transportation systems performance evaluation using fuzzy logic \\
\hline Rajaonson and Tanguay & 2017 & Cities & $\begin{array}{l}\text { A sensitivity analysis to methodological variation in indicator-based urban sustainability } \\
\text { assessment: a Quebec case study }\end{array}$ \\
\hline Reisi et al. & 2014 & Cities & Transport sustainability index: Melbourne case study \\
\hline Robati et al. & 2015 & Cities & Urban environment quality assessment by using composite index model \\
\hline Saleem et al. & 2018 & Infrastructure or building projects & Life cycle thinking-based selection of building facades \\
\hline Shi et al. & 2011 & Cities & Temporal changes in sustainable development level for Lijiang City \\
\hline Shmelev and Shmeleva & 2018 & Cities & Global urban sustainability assessment: a multidimensional approach \\
\hline Stender and Walter & 2018 & Infrastructure or building projects & The role of social sustainability in building assessment \\
\hline Tan et al. & 2018 & Cities & $\begin{array}{l}\text { A system dynamics model for simulating urban sustainability performance: a China case } \\
\text { study }\end{array}$ \\
\hline Ustaoglu et al. & 2017 & Infrastructure or building projects & $\begin{array}{l}\text { Scenario analysis of alternative land development patterns for the Leipzig-Halle region: } \\
\text { implications for transport-land-use sustainability }\end{array}$ \\
\hline Verseckiene et al. & 2017 & Transportation systems & $\begin{array}{l}\text { Evaluation of alternatives to integrate special transportation services for people with } \\
\text { movement disorders }\end{array}$ \\
\hline Wey and Huang & 2018 & Transportation systems & Urban sustainable transportation planning strategies for liveable city's quality of life \\
\hline Wu et al. & 2018 & Cities & Examining component-based city health by implementing a fuzzy evaluation approach \\
\hline
\end{tabular}


Table 3 (continued)

\begin{tabular}{|c|c|c|c|}
\hline Author & Year & Focus area & Title \\
\hline $\mathrm{Xu}$ and Coors & 2012 & Neighbourhoods & $\begin{array}{l}\text { Combining system dynamics model, GIS and 3D visualization in sustainability assessment of } \\
\text { urban residential development }\end{array}$ \\
\hline Yi et al. & 2019 & Cities & Assessment of city sustainability using MCDM with interdependent criteria weight \\
\hline Yigitcanlar et al. & 2015 & Neighbourhoods & $\begin{array}{l}\text { Towards prosperous sustainable cities: a multiscalar urban sustainability assessment } \\
\text { approach }\end{array}$ \\
\hline Zheng et al. & 2017 & Neighbourhoods & Neighborhood sustainability in urban renewal: an assessment framework \\
\hline Zope et al. & 2019 & Transportation systems & $\begin{array}{l}\text { Benchmarking: a tool for evaluation and monitoring sustainability of urban transport system } \\
\text { in metropolitan cities of India }\end{array}$ \\
\hline
\end{tabular}

category. However, most of them measure green space or park area in square metres, often in relation to the total population of the study area. Although most of the indicators in this category are quantitative, few qualitative or semiquantitative indicators can also be found, for example the assessment of harmony with the surroundings. Twenty-three percent of the indicators for the stakeholder group local community assess impacts on air quality. Most of the indicators in this category are quantitative, measuring air pollutant emissions. Nevertheless, mortality effects of air pollutants or actions to reduce air pollutants are additional measurements suggested in the reviewed literature. Indicators that evaluate impacts on local employment take third place with $16 \%$. In this category, the variety of indicators is much smaller, often measuring the same aspect formulated in different ways. The indicators primarily target job opportunities, job availabilities or unemployment rate. Indicators assessing noise pollution $(12 \%)$ and community engagement (8\%) follow. All of the indicators stated to measure noise pollution are quantitative; however, the indicators themselves differ a lot. Some measure the area in square metres, others the percentage of population that is affected by noise pollution and yet others suggest measuring noise complaint cases. The indicators that assess impacts on community engagement are mostly qualitative, targeting, for example, the degree of population participation, the degree of information access or the existence of a response system. Seven percent of the indicators target effects on space

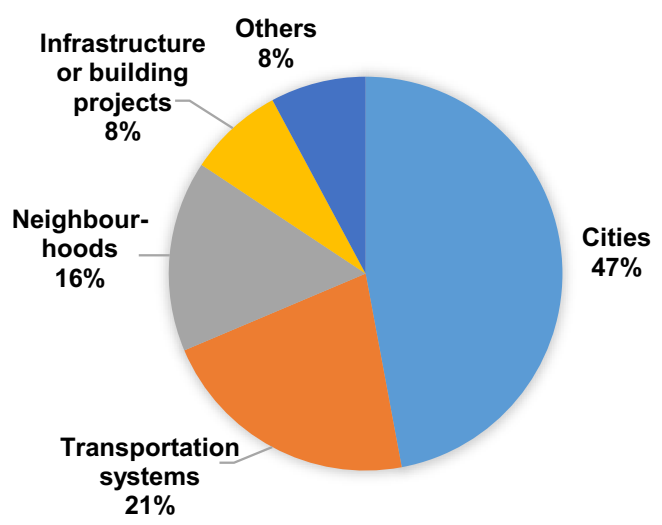

Fig. 3 Identified focus areas from indicators analysed occupancy. Here, again a great variety of indicators was found in the reviewed literature. Some indicators measure land consumption or green space destruction, and others focus on per capita area of paved roads or the proportion of land paved for transport facilities. Only $2 \%$ of the indicators focus on citizens' satisfaction measured either qualitatively (degree of social acceptance) or quantitatively (number of complaints or number of citizens satisfied with their local area). Three percent of the indicators measure other aspects not previously stated, such as light emissions or the impact on nonmotorised transportation.

Regarding the stakeholder group consumers, the majority of indicators target accessibility ( $41 \%)$. Here, the indicators partly assess the expansion of infrastructure, e.g. measuring the length of mass transport network or road density, and partly the transportation options itself, e.g. the number of transport points or the number of passengers per transport mode. Indicators assessing safety take the second position $(25 \%)$, followed by indicators assessing convenience $(11 \%)$. The indicators assessing safety can also be classified into indicators measuring the safety of the infrastructure, e.g. safe pedestrian pathways, and indicators assessing safety of the transport mode itself, e.g. mortality rate or accidents rate. The analysed indicators assessing convenience are mostly qualitative or semi-qualitative. They measure many different aspects ranging from thermal comfort and ventilation potential to supply the reliability and punctuality of deliveries.

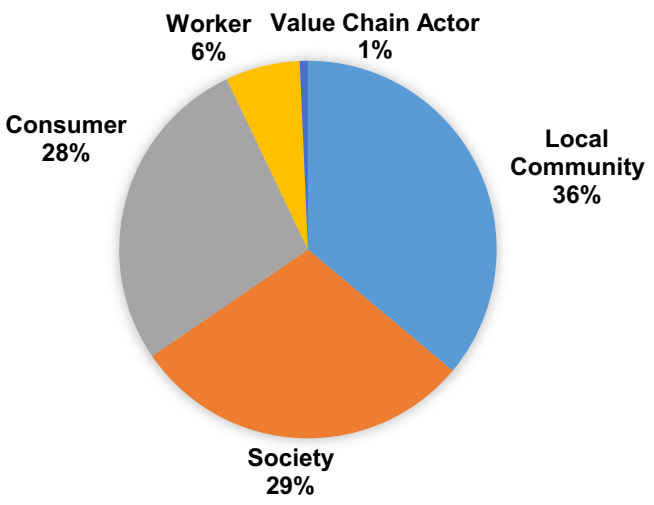

Fig. 4 Social indicators categorised by stakeholder groups from the 51 reviewed publications 


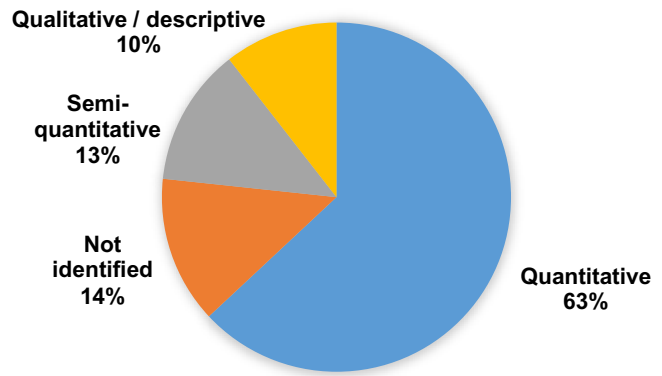

Fig. 5 Social indicators categorised by the type of indicator

Indicators targeting inclusiveness and affordability take the last place with 7\%, respectively. All of the reviewed indicators measuring inclusiveness are either semi-quantitative or qualitative. They evaluate, for example, inclusive design or the degree of universal access. Indicators assessing affordability, however, are mostly quantitative and measure e.g. household expenses on transportation or costs for public transport services. Nine percent of the indicators that assess impacts on consumers target other aspects, for example the average duration of travel to work or intermodal terminals.

The vast majority of indicators that assess impacts regarding the stakeholder group worker assess health and safety issues $(53 \%)$. Different aspects are suggested to measure in the reviewed literature for this category, mainly of quantitative nature, such as the number of fatal and non-fatal accidents or compensated occupational problems. However, semiquantitative indicators are also stated, for the assessment of work environment or appropriate working equipment. Thirteen percent of the indicators for workers assess fair salary. Here, not only the compensation itself is suggested to measure but also whether the workers are paid regularly. Nine percent of the indicators evaluate training and education, including the existence of educational programmes for selfdevelopment and the number of school absences of children. To evaluate discrimination, the suggested indicators (6\%) assess equality and diversity as well as whether formal policies against discrimination exist. Only small numbers $(3 \%)$ of indicators are found in the reviewed literature that evaluate child labour, freedom of association and collective bargaining as well as work-life balance. At this point, it should be highlighted that due to the selected search terms and the focus on mobility services, the stakeholder groups worker and value chain actors are underrepresented, as stated above (Fig. 4). Concerning the stakeholder group value chain actors, all of the identified indicators assess supplier relationships. It can therefore be assumed that other categories and indicators may need to be added for a holistic assessment. For the stakeholder group society, $63 \%$ of the analysed indicators assess health impacts, mainly in the form of $\mathrm{CO}_{2}$ emissions or other greenhouse gases. Twenty-five percent of the indicators focus on urban development and evaluate the existence of an urban development plan or compatibility with local urban mobility policies. Finally, $13 \%$ of the reviewed indicators of the stakeholder group society target tax income.

In Table 5, the filtered and grouped indicators are shown for the respective stakeholder groups, including information regarding indicator type and data availability (results of phase 3 ). For reasons of clarity and comprehensibility, indicators that are mentioned several times or evaluate the same aspect are only stated once. Overall, Table 5 not only demonstrates a huge variety and diversity of indicators intending to measure the same aspect. Many indicators are, in addition, not clearly defined, which makes them difficult to measure. The lack of concrete calculation methods in combination with a lack of data constitutes a major challenge and leads to the necessity for experts and decision-makers to select a calculation method of their own.

Therefore, on the basis of the above-stated analysis, a core set of indicators is proposed, including a description and concrete measurement for each indicator. For this core set of indicators, data availability and consultations of experts in the field of urban mobility were taken into account. For a holistic set of indicators, the results from the literature review were compared to the social topics, subcategories and indicators in the Guidelines and in the PSIA. Missing aspects, especially for the stakeholder groups workers and value chain actors, were added for a comprehensive assessment. Here again, only missing aspects that fulfil the defined precondition regarding relevance for the assessment of mobility services were added. This core set of indicators is presented in Table 6 (results of phase 4). For all core set indicators, a 5point scale from -2 to +2 is defined, including underlying performance reference points. In addition to Table 6 , the reference scale and performance reference points can be found in Table 7 (quantitative indicators) and Table 8 (qualitative indicators).

For the assessment of impacts regarding public space, the majority of indicators focus on the assessment of green areas or public open space (see Table 5). Mobility services, just like other transportation systems, require infrastructure, which may lead to green space destruction. At the same time, higher efficiency or occupancy rate may also lead to less space occupancy and, consequently, to new possibilities for green or open space. Therefore, an indicator evaluating these aspects is essential and included in the core set. For the evaluation of air quality, relevant air pollutants, as suggested in the reviewed literature, are selected and measured per passenger kilometre. For the effects on employment, two indicators are suggested for the core set. One measures the percentage of employees hired and the other the percentage of employees hired locally during the study period. In that way, general job creation as well as local effects can be measured. For the assessment of noise pollution, two main assessment methods were identified. One targets the populated area in square metres that is exposed to noise pollution (Mansourianfar and 
Table 4

Analysis of the indicators and allocation to stakeholder group (count and type of indicator)

\begin{tabular}{|c|c|c|c|c|c|c|c|}
\hline Author & Year & Focus area & Local community & Consumers & Worker & Value chain actors & Society \\
\hline Ameen and Mourshed & 2019 & Cities & $12 \mathrm{~d}$ & $11 \mathrm{~d}$ & $2 \mathrm{~d}$ & & $11 \mathrm{~d}$ \\
\hline Anisurrahman and Alshuwaikhat & 2019 & Cities & $3 \mathrm{~s}$ & $3 \mathrm{~s}$ & & & $8 \mathrm{~s}$ \\
\hline Aparcana and Salhofer & 2013 & Others & & & $26 \mathrm{~s}$ & & \\
\hline Azami et al. & 2015 & Cities & $2 \mathrm{q}$ & $1 \mathrm{q}$ & & & $4 \mathrm{q}$ \\
\hline Bandeira et al. & 2018 & Transportation systems & $3 \mathrm{q}$ & $1 \mathrm{q}$ & & & $1 \mathrm{q}$ \\
\hline Bui et al. & 2017 & Others & $5 \mathrm{q}$ & & $3 q$ & & \\
\hline de Oliveira Cavalcanti et al. & 2017 & Cities & $4 \mathrm{q}$ & $8 \mathrm{q}$ & & & $1 \mathrm{q}$ \\
\hline Choon et al. & 2011 & Cities & $3 \mathrm{q}$ & $2 \mathrm{q}$ & & & $6 \mathrm{q}$ \\
\hline Ding et al. & 2015 & Cities & 2 n.i. & 2 n.i. & & & 1 n.i. \\
\hline Dizdaroglu and Yigitcanlar & 2014 & Neighborhoods & $3 \mathrm{q}$ & $1 \mathrm{q}$ & & & \\
\hline Dur et al. & 2014 & Neighborhoods & $9 \mathrm{q}$ & $9 \mathrm{q}$ & & & $1 \mathrm{q}$ \\
\hline Feleki et al. & 2018 & Cities & $8 \mathrm{q}$ & $2 \mathrm{q}$ & & & $1 \mathrm{q}$ \\
\hline Fouda and Elkhazendar & 2019 & Cities & $9 \mathrm{q}$ & $4 q$ & & & $11 \mathrm{q}$ \\
\hline Gonzalez-Garcia et al. & 2018 & Cities & $2 \mathrm{q}$ & $2 \mathrm{q}$ & & & $4 \mathrm{q}$ \\
\hline Haghshenas and Vaziri & 2012 & Cities & $2 \mathrm{q}$ & $4 \mathrm{q}$ & & & \\
\hline Harijani et al. & 2017 & Others & $4 \mathrm{~d}$ & $1 \mathrm{~d}$ & $1 \mathrm{~d}$ & $1 \mathrm{~d}$ & \\
\hline Hély and Antoni & 2019 & Cities & $5 \mathrm{~d}$ & $3 \mathrm{~d}$ & & & \\
\hline Jasti and Ram & 2018 & Transportation systems & 1 q, 1 n.i. & 8 q, 1 n.i. & & & \\
\hline Kawakubo et al. & 2018 & Cities & $7 \mathrm{q}$ & $1 \mathrm{q}$ & & & $14 \mathrm{q}$ \\
\hline Laprise et al. & 2018 & Neighborhoods & $19 \mathrm{~s}$ & $5 \mathrm{~s}$ & & & $5 \mathrm{~s}$ \\
\hline $\mathrm{Li}$ and $\mathrm{Li}$ et al. & 2017 & Cities & $6 \mathrm{q}$ & $2 \mathrm{q}$ & & & $2 \mathrm{q}$ \\
\hline Lu et al. & 2017 & Neighborhoods & $4 \mathrm{q}$ & & & & $7 \mathrm{q}$ \\
\hline Lu et al. & 2016 & Cities & $6 \mathrm{q}$ & & & & $3 \mathrm{q}$ \\
\hline Mansourianfar and Haghshenas & 2018 & Infrastructure or building projects & $5 \mathrm{q}$ & $2 \mathrm{q}$ & & & \\
\hline Mapar et al. & 2017 & Cities & 9 n.i. & 7 n.i. & 3 n.i. & 3 n.i. & 15 n.i. \\
\hline Miller et al. & 2016 & Transportation systems & $5 \mathrm{q}$ & $9 \mathrm{q}$ & & & \\
\hline Onat et al. & 2014 & Transportation systems & $3 \mathrm{q}$ & & $2 \mathrm{q}$ & & $1 \mathrm{q}$ \\
\hline Opher et al. & 2018 & Others & $1 \mathrm{q}, 2 \mathrm{~d}$ & $2 \mathrm{q}, 4 \mathrm{~d}$ & & & $1 \mathrm{q}, 1 \mathrm{~d}$ \\
\hline Oregi et al. & 2016 & Neighborhoods & $3 \mathrm{~s}$ & $2 \mathrm{~s}$ & & & $3 \mathrm{~s}$ \\
\hline Oses et al. & 2017 & Transportation systems & $4 \mathrm{q}$ & $3 \mathrm{q}$ & & & $1 \mathrm{q}$ \\
\hline Oswald Beiler and Mohammed & 2016 & Transportation systems & $1 \mathrm{q}$ & $3 \mathrm{q}$ & & & $2 \mathrm{q}$ \\
\hline Papoutsis et al. & 2018 & Transportation systems & $5 \mathrm{q}$ & $3 \mathrm{q}$ & & & \\
\hline Phillis et al. & 2017 & Cities & $6 \mathrm{q}$ & $1 \mathrm{q}$ & & & $16 \mathrm{q}$ \\
\hline Rajak et al. & 2016 & Transportation systems & 1 q, 7 n.i. & 3 q, 8 n.i. & & & 2 q, 2 n.i. \\
\hline Rajaonson and Tanguay & 2017 & Cities & $5 \mathrm{q}$ & $1 \mathrm{q}$ & & & $7 \mathrm{q}$ \\
\hline Reisi et al. & 2014 & Cities & $2 \mathrm{q}$ & $3 \mathrm{q}$ & & & $1 \mathrm{q}$ \\
\hline Robati et al. & 2015 & Cities & $2 \mathrm{q}$ & $1 \mathrm{q}$ & & & $2 \mathrm{q}$ \\
\hline Saleem et al. & 2018 & Infrastructure or building projects & $1 \mathrm{q}$ & & & & \\
\hline Shi et al. & 2011 & Cities & $3 \mathrm{q}$ & & & & $3 \mathrm{q}$ \\
\hline Shmelev and Shmeleva & 2018 & Cities & & & & & $3 \mathrm{q}$ \\
\hline Stender and Walter & 2018 & Infrastructure or building projects & $3 \mathrm{~d}$ & & & & \\
\hline Tan et al. & 2018 & Cities & $4 \mathrm{q}$ & $1 \mathrm{q}$ & & & $4 \mathrm{q}$ \\
\hline Ustaoglu et al. & 2017 & Infrastructure or building projects & 3 n.i. & 9 n.i. & & & \\
\hline Verseckiene et al. & 2017 & Transportation systems & $2 \mathrm{q}$ & 1 q, 6 n.i. & & & $1 \mathrm{q}$ \\
\hline Wey and Huang & 2018 & Transportation systems & $2 \mathrm{q}$ & $3 q$ & & & $1 \mathrm{q}$ \\
\hline Wu et al. & 2018 & Cities & $8 \mathrm{q}$ & $2 \mathrm{q}$ & & & $5 \mathrm{q}$ \\
\hline $\mathrm{Xu}$ and Coors & 2012 & Neighborhoods & $2 \mathrm{q}$ & $1 \mathrm{q}$ & & & $5 \mathrm{q}$ \\
\hline Yi et al. & 2019 & Cities & $4 \mathrm{q}$ & & & & $4 \mathrm{q}$ \\
\hline Yigitcanlar et al. & 2015 & Neighborhoods & $4 \mathrm{q}$ & $7 \mathrm{q}$ & & & \\
\hline
\end{tabular}


Table 4 (continued)

\begin{tabular}{|c|c|c|c|c|c|c|}
\hline Author & Year & Focus area & Local community & Consumers Worker & Value chain actors & Society \\
\hline Zheng et al. & 2017 & Neighborhoods & $7 \mathrm{q}$ & $2 \mathrm{q}$ & & $8 \mathrm{q}$ \\
\hline Zope et al. & 2019 & Transportation systems & $2 \mathrm{q}$ & $4 \mathrm{q}$ & & $2 q$ \\
\hline
\end{tabular}

q, quantitative indicator(s); s, semi-quantitative indicators; d, qualitative (descriptive) indicator(s); n.i., indicator type not identified

Haghshenas 2018; Fouda and Elkhazendar 2019), and the other measures the hindrance of population by traffic noise based on a weighting factor for population density (Oses et al. 2017). Due to the difficult data situation for noise pollution, both indicators were adopted for the core set and can be applied according to data availability. For the evaluation of community engagement, though, the literature review presents many different qualitative indicators and, often, a clear assessment method is not stated in the respective publications (Mapar et al. 2017; Laprise et al. 2018; Ameen and Mourshed 2019). Therefore, it is proposed to use the qualitative, scalebased assessment method according to the PSIA, which evaluates the degree of population participation. This international handbook offers a transparent and clearly defined 5-point scale from -2 to +2 , including underlying performance indicators, that is already internationally recognised for the assessment of community engagement (Goedkoop et al. 2018). This type of assessment method is part of type I impact assessment (see Fig. 1). A major advantage and reason for the selection of this type of assessment approach is the possibility to measure positive as well as negative impacts.

As previously mentioned, the literature review revealed various indicators for the assessment of space occupancy, often with a focus on a specific transportation mode. For the core set, however, the indicators stated in the literature are summarised and generalised. That way, three indicators are suggested for the core set, namely direct and indirect space occupancy for the different mobility modes in relation to passenger kilometre and in relation to the total study area. Direct space occupancy refers to e.g. roads, cycle lanes or railways, whereas indirect space occupancy refers to open or private parking, stations, service areas or petrol stations (WBCSD 2015). As data availability might be limited for this indicator, space occupancy (excluding infrastructure) in relation to green and open space is also included. Hereby, the different indicators can be applied according to data availability. In the reviewed literature, $2 \%$ of the indicators evaluate citizens' satisfaction. However, the indicator evaluating community engagement already includes citizens' opinion and the possibility to give feedback, which is why this aspect is not included additionally in the core set.

As already stated, two main aspects were identified in the reviewed literature to evaluate accessibility for the stakeholder group consumers. One is the expansion of infrastructure, e.g. the length of mass transport network or road density and the other transportation options itself, e.g. the number of transport points or the number of passengers per transport mode. For the core set, the latter is selected, as the expansion of infrastructure is difficult to capture with one single indicator that is suitable for the different mobility options (Robati et al. 2015; Li and Li 2017; Fouda and Elkhazendar 2019). Out of the indicators that were suggested in the literature to assess safety of consumers, the number of fatal and non-fatal accidents in relation to passenger kilometre was adopted as a quantitative indicator, for data availability reasons. As previously mentioned, diverse indicators were found in the literature to measure convenience, most of them of qualitative or semi-qualitative nature. However, with the aim of quantifying convenience and for data availability reasons, punctuality of deliveries was selected for the core set, measuring the number of punctual trips in relation to the total number of trips. For mobility options, which can be used on demand without waiting time, zero delayed trips can be assumed. This indicator supplements the indicator selected for accessibility, as the number of transport points within the study area also indirectly affects convenience. The higher the number of e.g. car-sharing cars or electric scooters within the study area, the lower the necessary walking time to the nearest transport point, which, in turn, leads to higher convenience. For the assessment of inclusiveness, all of the indicators in the reviewed literature were either semi-quantitative or qualitative or the assessment method was not stated (Verseckiene et al. 2017; Jasti and Ram 2018). This emphasises the difficulty to quantify inclusiveness. Therefore, the scale-based indicator as stated in the PSIA with the already mentioned clearly defined 5-point scale with corresponding performance indicators is suggested for the core set (Goedkoop et al. 2018). For the assessment of affordability, however, a quantitative indicator is selected, evaluating the trip fare for different transport modes in relation to average income. This way, local income differences can be considered. Although no indicators were found in the reviewed literature that measure data privacy or evaluate consumers' feedback, these two indicators were stated in the Guidelines and in the PSIA (see also Table 2). Therefore, these two indicators were included in the core set. For the assessment of data privacy, the scale-based approach was adopted according to the PSIA (Goedkoop et al. 2018), whereas to measure consumer satisfaction, the number of consumer complaints was selected based on the Guidelines (UNEP/SETAC 2013). 
Table 5 Most frequently assessed categories and indicators used for the respective stakeholder groups

\begin{tabular}{llll}
\hline Category & $\begin{array}{l}\text { Frequency } \\
\text { in } \%\end{array}$ & Indicator & $\begin{array}{l}\text { Type of } \\
\text { indicator }\end{array}$ \\
\hline
\end{tabular}

Local community

Public space

Air quality

Local employment

Noise pollution

\section{Consumers}

Accessibility
Public access to open space

Green space area in $\mathrm{m}^{2} /$ total number of population

Green areas availability

Ratio green coverage of built-up areas

Per capita park green area

Harmony with the surroundings

Proximity to green spaces

Coverage of public green space in built area

Averaged green space per resident $\left(\mathrm{m}^{2}\right.$ per capita)

Land use change

Land use mix

Concentration of air pollutant gases and particulates in microgram $/ \mathrm{m}^{3}$

Particulate matter formation potential (PMFP) based on ReCiPe

Number of days with exceeded thresholds for monitored concentrations of Quantitative $\mathrm{SO}_{2}, \mathrm{NO}_{2}, \mathrm{CO}, \mathrm{O}_{3}, \mathrm{PM}_{10}$ and $\mathrm{PM}_{2.5}$

Average annual emissions of $\mathrm{NO}_{2}$

Total health/medical costs, crop losses, building damages, etc., caused by the impacts of air pollution

Emission intensity of air pollutants $\left(\mathrm{SO}_{2}, \mathrm{CO}, \mathrm{NO}_{x}, \mathrm{PM}_{10}\right.$ and $\left.\mathrm{PM}_{2.5}\right) / \mathrm{km}$ Emissions of particles per year (\%)

Air quality index

Mortality effects of air pollutants

Actions to reduce air pollutant emissions

Creating job opportunities

Maintenance work hours

Number of employees

Proportion of work carried out by local companies

Jobs availability

Disposable income of urban residents

Unemployment rate

$\%$ area inhabited exposed to traffic noise pollution greater than $65 \mathrm{~dB}$

Exposure to noise level above $65 \mathrm{~dB}$ in $\mathrm{m}^{2}$

Percent of noise pollution exceeding national standard (\%)

Average emissions of noise

Noise complaint cases

Reclamation system

Participatory process

Social cohesion

Local residents participation in planning process

Stakeholder consultation

Degree of population participation

Degree of information access

Degree of integration of an evaluation process

Existence of a direct participation structure

Existence of quick response system

Space occupancy in $\mathrm{m}^{2}$

Land consumption in $\mathrm{m}^{2}$

Green space destruction

Land area consumed by transit facilities

Per capita area of paved roads

Portion of land paved for transport facilities

Surface for transportation infrastructure

Social acceptance

Total number of complaints

Total number of citizens satisfied with their local area

Light pollution

Degree of prevention of light emissions

Impact on non-motorised transport
Number of transport points within the study area

Number of passengers

Transport diversity/integration

Public transport to work (\%)
Quantitative 2

Quantitative 2

Semi-quantitative 2

Quantitative 2

Quantitative 2

Qualitative 1

Semi-quantitative 1

Quantitative 2

Quantitative 2

n.i.

Quantitative

Quantitative

Quantitative 3

Quantitative 3

Quantitative

Quantitative 3

Quantitative 3

Quantitative 3

Quantitative 1

Semi-quantitative 2

Qualitative 1

Quantitative 2

Quantitative 3

Semi-quantitative 1

Semi-quantitative 1

Quantitative 2

Quantitative 3

Quantitative 1

Quantitative 1

Quantitative 2

Quantitative 2

Quantitative 1

Qualitative 2

Qualitative 2

Qualitative 1

Semi-quantitative 2

Qualitative 2

Semi-quantitative 1

Semi-quantitative 1

Semi-quantitative 1

Qualitative 2

Qualitative 2

Quantitative 2

Quantitative 2

Quantitative 1

Quantitative 1

Quantitative 1

Quantitative 1

Quantitative 1

Qualitative 1

Quantitative 1

Quantitative 1

Semi-quantitative 1

Semi-quantitative 1

Semi-quantitative 1

Quantitative 1

Quantitative 2

n.i.

Quantitative 1 
Table 5 (continued)

\begin{tabular}{|c|c|c|c|c|}
\hline Category & $\begin{array}{l}\text { Frequency } \\
\text { in } \%\end{array}$ & Indicator & $\begin{array}{l}\text { Type of } \\
\text { indicator }\end{array}$ & $\begin{array}{l}\text { Data } \\
\text { availability }\end{array}$ \\
\hline & & Length of mass transport network & Quantitative & 2 \\
\hline & & Public transport service availability & Semi-quantitative & 1 \\
\hline & & Bicycle path availability & Semi-quantitative & 1 \\
\hline & & Improvement in the connectivity & Qualitative & 1 \\
\hline & & Diversity of transport modes & Semi-quantitative & 2 \\
\hline & & Road density & Quantitative & 2 \\
\hline & & Kilometres of total rail lines & Quantitative & 2 \\
\hline & & Public transit ridership ( $\%$ of transit commuters) & Quantitative & 2 \\
\hline & & Passenger vehicle kilometres & Quantitative & 1 \\
\hline \multirow[t]{11}{*}{ Safety } & 25 & Quality of products & Qualitative & 1 \\
\hline & & Security by design & Qualitative & 1 \\
\hline & & Protection from high temperatures and sunlight & Qualitative & 1 \\
\hline & & Fatal and non-fatal traffic accidents & Quantitative & 2 \\
\hline & & Average crash frequency & Quantitative & 2 \\
\hline & & Degree of security & Semi-quantitative & 1 \\
\hline & & Mortality rate & Quantitative & 2 \\
\hline & & Accidents rate & Quantitative & 2 \\
\hline & & Safe pedestrian pathways & n.i. & 1 \\
\hline & & Safe urban road networks & n.i. & 1 \\
\hline & & Safety for elderly and disabled people & n.i. & 1 \\
\hline \multirow[t]{9}{*}{ Convenience } & 11 & Supply reliability & Qualitative & 1 \\
\hline & & Ventilation potential & Semi-quantitative & 1 \\
\hline & & Daylight availability & Semi-quantitative & 1 \\
\hline & & Thermal comfort & Semi-quantitative & 1 \\
\hline & & Smart and appropriate location & Semi-quantitative & 1 \\
\hline & & Transport performance & Qualitative & 1 \\
\hline & & Quality of service & Semi-quantitative & 1 \\
\hline & & Punctuality of deliveries & Semi-quantitative & 2 \\
\hline & & Traffic congestion & n.i. & 1 \\
\hline \multirow[t]{4}{*}{ Inclusiveness } & 7 & Inclusive design (ageing and disabled) & Qualitative & 1 \\
\hline & & Adaptation for social inclusion & Qualitative & 1 \\
\hline & & Potential of social diversity & Semi-qualitative & 1 \\
\hline & & Degree of universal access & Semi-qualitative & 1 \\
\hline \multirow[t]{3}{*}{ Affordability } & 7 & Household expenses on transportation & Quantitative & 2 \\
\hline & & Travel costs & Semi-quantitative & 2 \\
\hline & & Costs for public transport services & Quantitative & 3 \\
\hline \multirow[t]{3}{*}{ Other } & 9 & Average duration of travel to work & Quantitative & 1 \\
\hline & & Intermodal terminals & Semi-quantitative & 2 \\
\hline & & Commuting distance & Quantitative & 1 \\
\hline \multicolumn{5}{|c|}{ 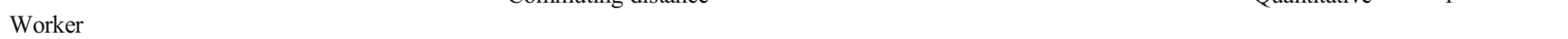 } \\
\hline \multirow[t]{10}{*}{ Health and safety } & 53 & $\begin{array}{l}\text { Human health-DALY-the number of years lost due to disability, illness or } \\
\text { early death }\end{array}$ & Quantitative & 2 \\
\hline & & Number of fatal and non-fatal injuries & Quantitative & 3 \\
\hline & & Damage to worker & Semi-quantitative & 1 \\
\hline & & Work environment & Semi-quantitative & 1 \\
\hline & & Occupational accidents & Quantitative & 3 \\
\hline & & Occupational diseases & Quantitative & 2 \\
\hline & & Number of fatalities at work per year & Quantitative & 3 \\
\hline & & Compensated occupational problems & Quantitative & 2 \\
\hline & & Appropriate working equipment & Semi-quantitative & 2 \\
\hline & & Vaccination for workers & Quantitative & 2 \\
\hline \multirow[t]{3}{*}{ Fair salary } & 13 & The compensation of employees, wages and salaries & Quantitative & 3 \\
\hline & & Minimum income according to legal framework & Quantitative & 3 \\
\hline & & Regular payment for the workers & Semi-quantitative & 2 \\
\hline \multirow[t]{2}{*}{ Training and education } & 9 & Existence of educational programmes for self-development & Semi-quantitative & 2 \\
\hline & & No school absence of children & Semi-quantitative & 3 \\
\hline \multirow[t]{2}{*}{ Discrimination } & 6 & Formal policy against discrimination & Semi-quantitative & 2 \\
\hline & & Equality and diversity & n.i. & 1 \\
\hline Child labour & 3 & No child labour & Semi-quantitative & 2 \\
\hline $\begin{array}{l}\text { Freedom of association and } \\
\text { collective bargaining }\end{array}$ & 3 & Presence of collective bargaining & Semi-quantitative & 2 \\
\hline Work-life balance & 3 & Fulfilment of overtime agreed in working contracts & Semi-quantitative & 2 \\
\hline \multirow[t]{2}{*}{ Other } & 9 & Willingness to continue working in the same company or sector & Semi-quantitative & 2 \\
\hline & & Work satisfaction & Semi-quantitative & 3 \\
\hline
\end{tabular}


Table 5 (continued)

\begin{tabular}{|c|c|c|c|c|}
\hline Category & $\begin{array}{l}\text { Frequency } \\
\text { in } \%\end{array}$ & Indicator & $\begin{array}{l}\text { Type of } \\
\text { indicator }\end{array}$ & $\begin{array}{l}\text { Data } \\
\text { availability }\end{array}$ \\
\hline & & Willingness to be trained regarding the work activities & Semi-quantitative & 4 \\
\hline \multicolumn{5}{|l|}{ Value chain actors } \\
\hline Supplier relationships & 100 & Supplier relationships & Semi-quantitative & 2 \\
\hline \multicolumn{5}{|l|}{ Society } \\
\hline \multirow[t]{5}{*}{ Health } & 63 & $\mathrm{CO}_{2}$ emissions & Quantitative & 3 \\
\hline & & $\mathrm{CO}_{2}$-eq emissions & Quantitative & 3 \\
\hline & & Greenhouse gases & Quantitative & 3 \\
\hline & & Acidification potential & Quantitative & 3 \\
\hline & & Eutrophication & Quantitative & 3 \\
\hline \multirow[t]{2}{*}{ Urban development } & 25 & Existence of urban development plans & Qualitative & 1 \\
\hline & & Compatibility with local urban mobility policies & Semi-quantitative & 2 \\
\hline Tax income & 13 & Taxes per $\mathrm{km}$ & Quantitative & 1 \\
\hline
\end{tabular}

Data availability: (1) limited, may require special data collection; (2) often available but not standardised; and (3) usually available in standardised form

The reviewed literature revealed that the majority of indicators assessing impacts on the stakeholder group worker evaluate health and safety issues. Therefore, the indicator that measures the number of fatal and non-fatal injuries was selected for the core set as a quantitative indicator with good data availability (Onat et al. 2014; Bui et al. 2017). For the evaluation of remuneration, though, two indicators were included in the core set of indicators. The first indicator measures a combination of wages and social benefits received by workers, a scale-based indicator as proposed by the PSIA. This indicator was included, as it not only assesses the wages for workers but also comprises social benefits. The second indicator measures the percentage of workers whose wages meet at least legal or industry minimum standards. This indicator was added to the core set of indicators, especially for the application in countries where violation of the law regarding minimum wage is a problem. This indicator might not be of relevance in every country. Hence, it can be used depending on the respective legal environment. For the assessment of discrimination, no clearly defined assessment method was stated in the reviewed literature (Aparcana and Salhofer 2013; Ameen and Mourshed 2019). As the PSIA suggests a scale-based indicator to evaluate prevention of discrimination, this assessment method was adopted. Only a few indicators were found in the reviewed literature regarding child labour, freedom of association and collective bargaining as well as work-life balance with again no clearly stated assessment method (Aparcana and Salhofer 2013). This is why, for the assessment of these aspects, the suggested scale-based indicators of the PSIA were adopted again. When comparing the indicators that were found in the reviewed literature to the indicators that are stated in the Guidelines as well as in the PSIA (Table 1), one can see that forced labour is suggested for evaluation in both the Guidelines and the PSIA, which, however, was not found in the reviewed literature. This is why the assessment of forced labour is included in the core set. For the assessment method, the scale-based indicator as stated in the PSIA was selected for consistency reasons. The literature review revealed that, in addition, $9 \%$ of the indicators evaluate training and education possibilities. Though, one of the two selected indicators for the evaluation of remuneration measures a combination of wages and social benefits. The social benefits comprise training and education possibilities. This is why no indicator evaluating training and education is included additionally in the core set.

Similar to the approach for the stakeholder group workers, the indicators found for the stakeholder group value chain actors were compared to the indicators stated in the Guidelines and in the PSIA and missing aspects were added to the core set. In the case of value chain actors, only supplier relationships were evaluated in the reviewed literature, as already mentioned. Therefore, the assessment of fair competition and intellectual property rights, as well as promoting social responsibility, was added for a holistic evaluation (Table 1). Here again, the adoption of a 5-point scale from -2 to +2 is proposed in order to be consistent. The proposed 5-point scale including underlying performance indicators can be found in Table 8. For the evaluation of social responsibility promotion, a quantitative indicator assessing the percentage of audited suppliers is additionally included in the core set, as suggested by the Guidelines (UNEP/SETAC 2013). Depending on data availability, one or the other indicator can be selected.

For the assessment of impacts on the stakeholder group society, the indicators that were found in the reviewed literature mainly evaluate health impacts in the form of greenhouse gases and other emissions that affect society as a whole $(63 \%)$. Here, the suggestions from the reviewed literature were followed and indicators assessing global warming potential, acidification potential and eutrophication potential were included in the core set. Another important aspect revealed by the literature review is the existence of an urban development plan and the extent to which the mobility company is engaging with city authorities for the promotion of urban development. Hence, this indicator is included in the core set with the 

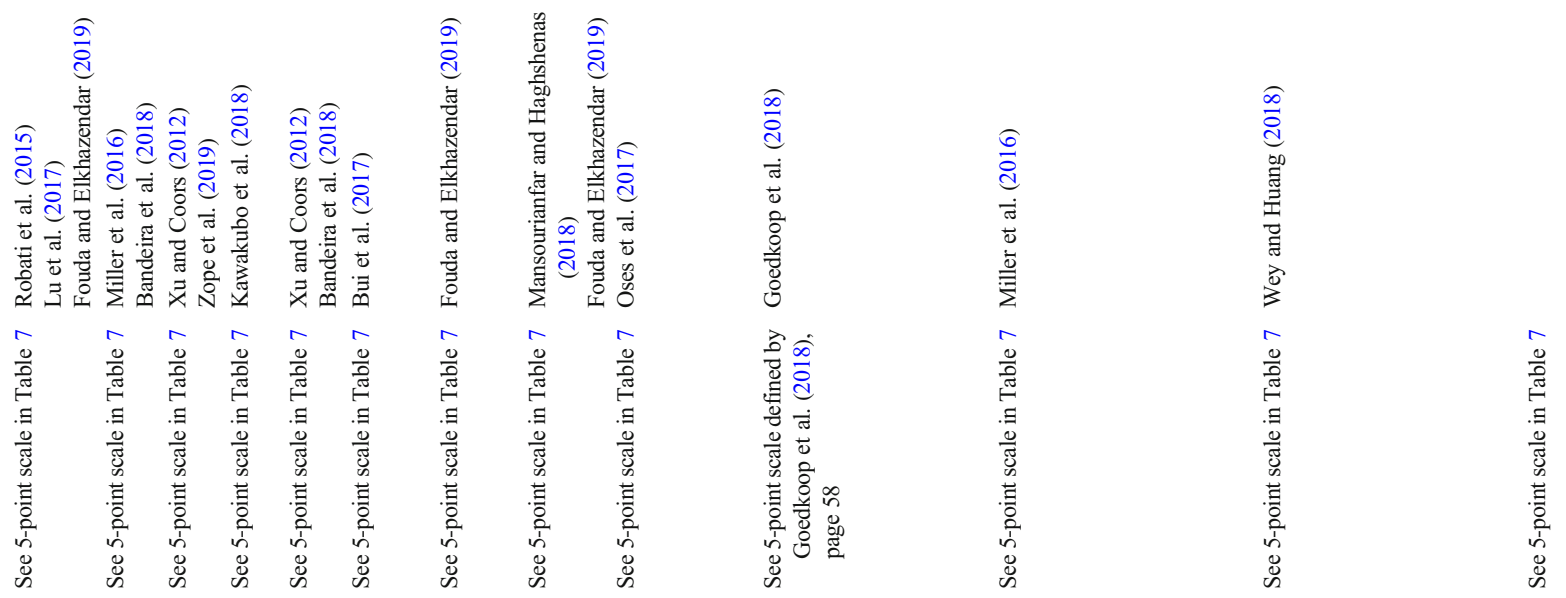

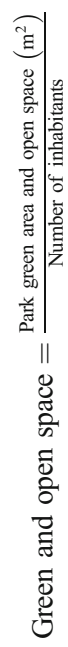

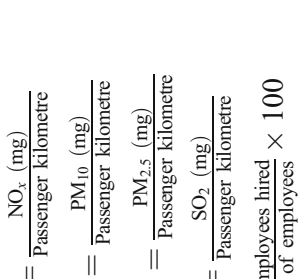

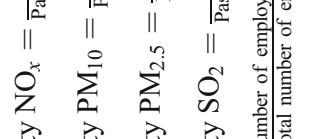
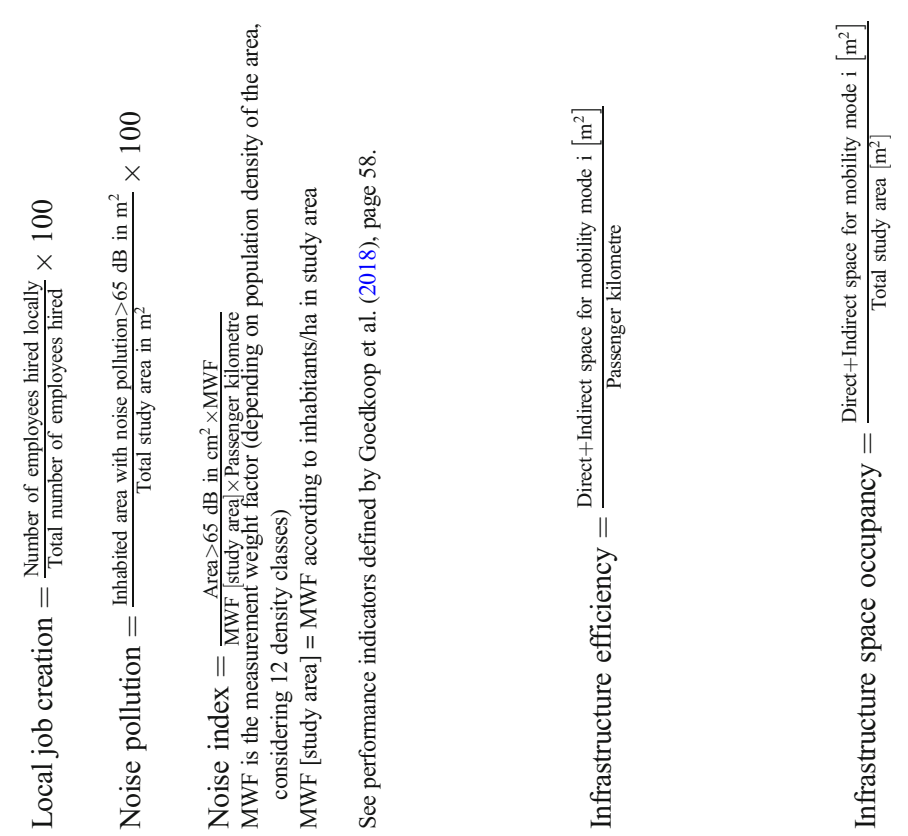

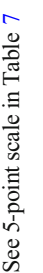

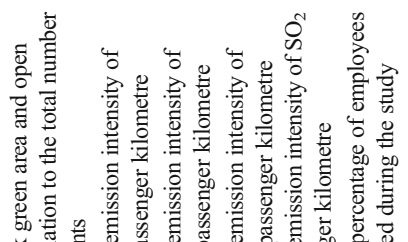

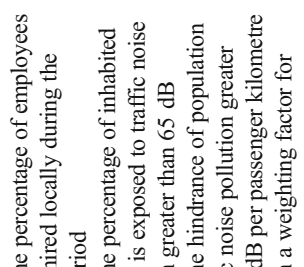

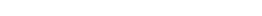

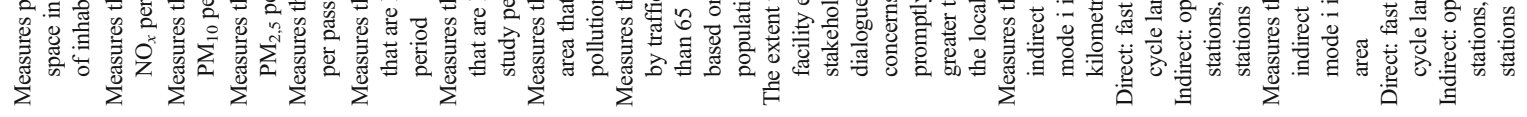
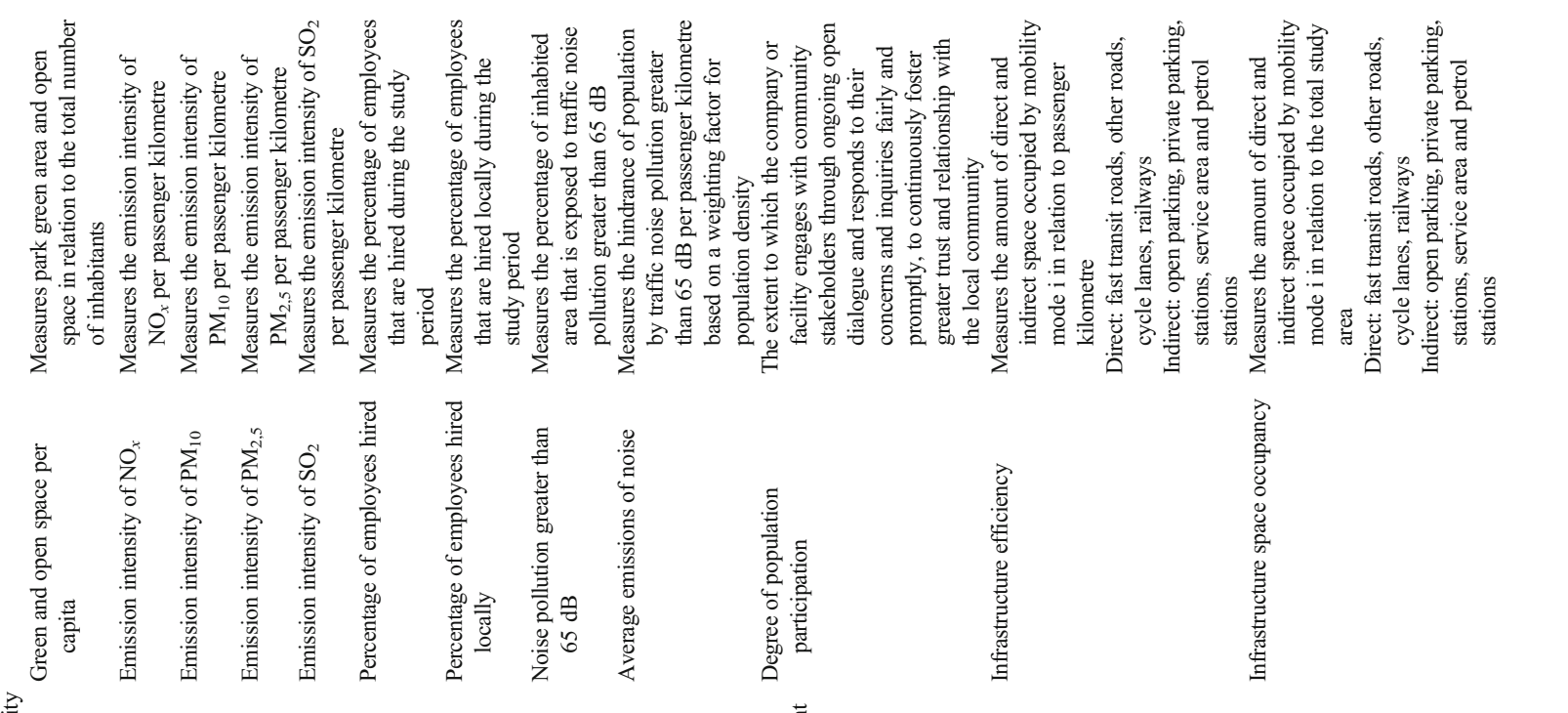


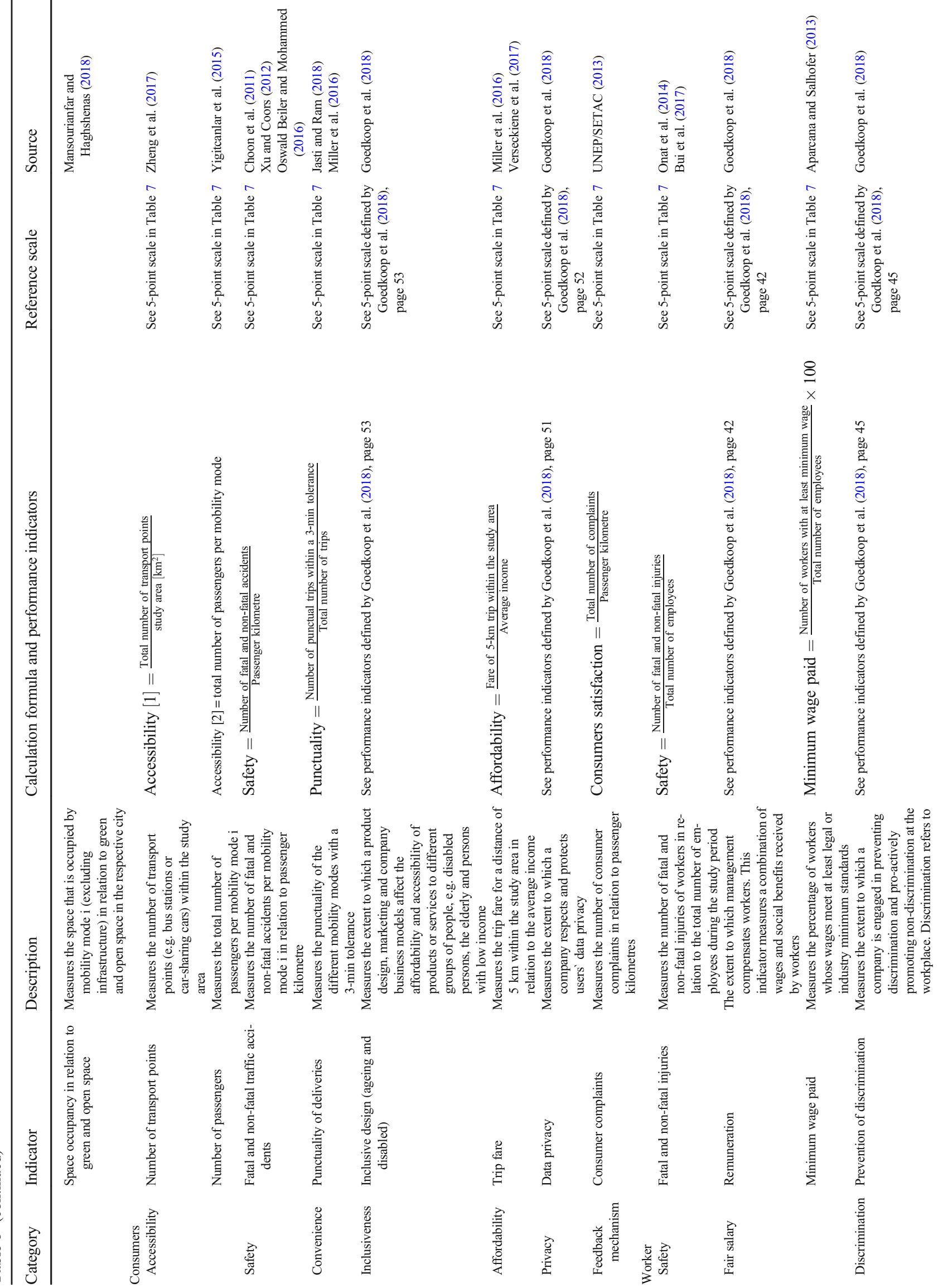



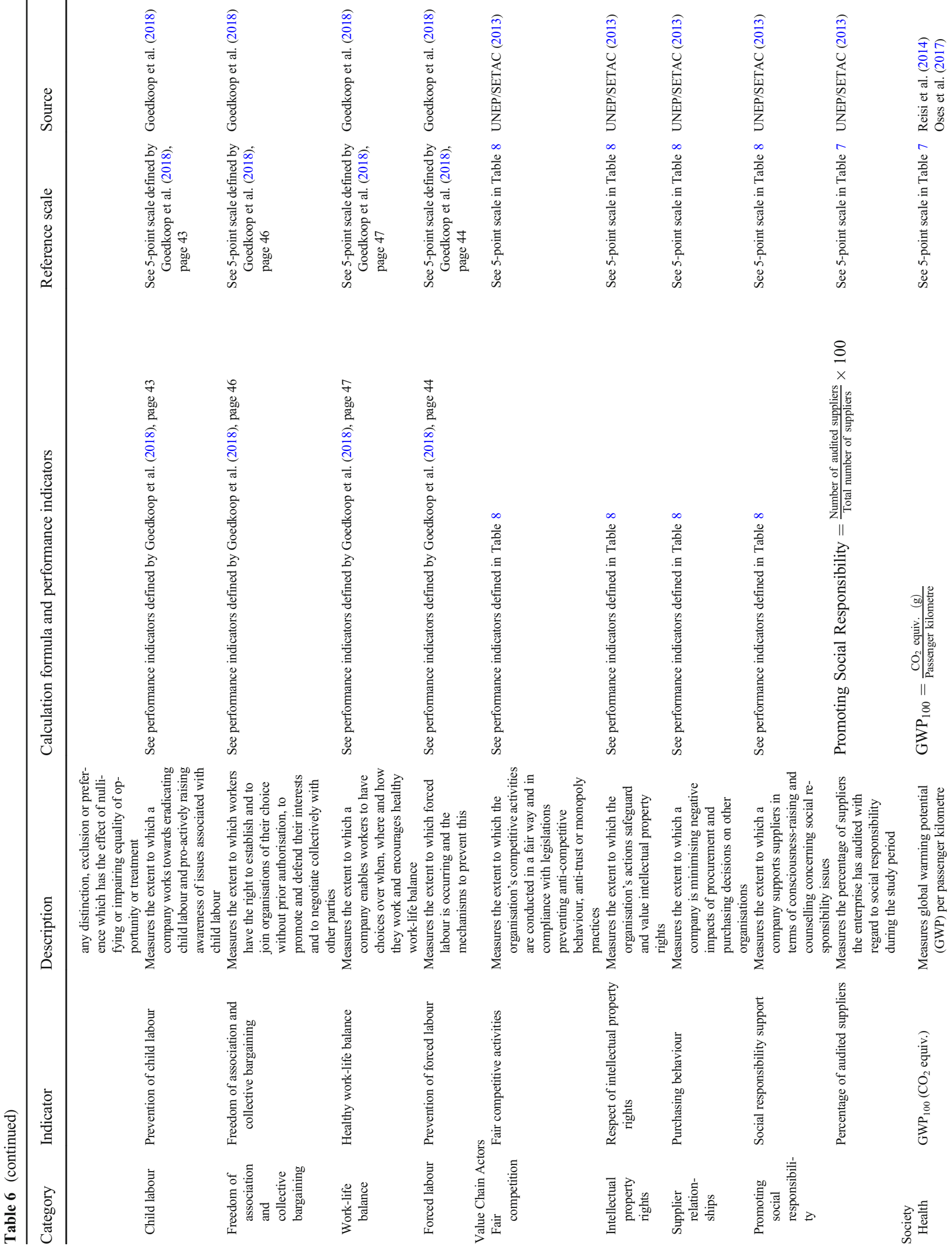


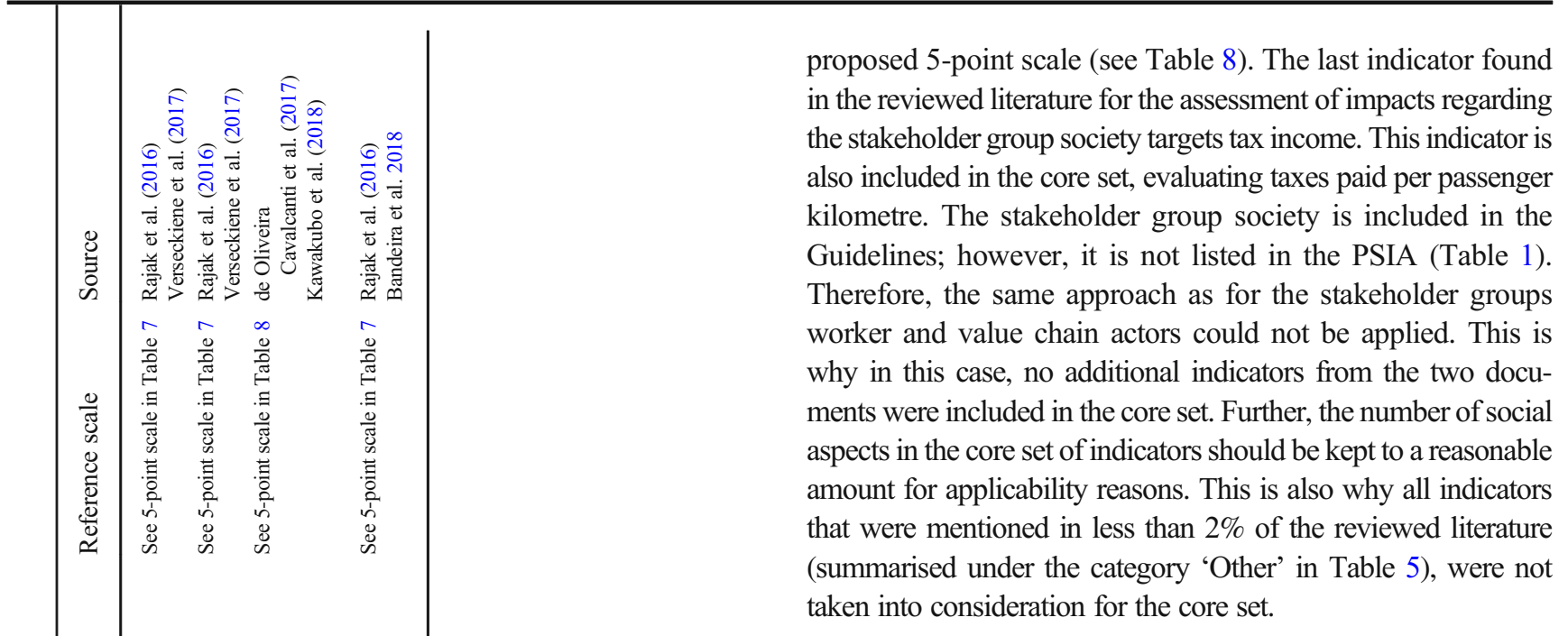

\section{Conclusion and recommendations}

The UNEP/SETAC Guidelines as well as the PSIA handbook substantially contributed to the progress in S-LCA. Whereas different S-LCA indicators and impact assessment methods have been applied and tested in a number of case studies, the use phase has been underrepresented in previous S-LCA case studies and there is still uncertainty regarding use phase evaluation. Use phase impacts, however, play an important role for the assessment of mobility services. Both the Guidelines and the PSIA present different subcategories and social topics for the stakeholder group consumers or users, but still they are not enough to assess products and services where the use phase plays a prevalent role, such as mobility services or a building. This gap is analysed in this paper by starting with a critical literature review. The focus of the literature review on the use phase aims to supplement other life cycle stages of mobility, for which the UNEP/SETAC Guidelines as well as the PSIA handbook have already been applied and tested (Ekener-Petersen et al. 2014; Chang et al. 2015; Reuter 2016; Zanchi et al. 2018).

The literature review was necessary to categorise and systematically analyse indicators that were used for the assessment of urban mobility in previous studies. In total, 579 indicators were identified, analysed and grouped according to the stakeholder groups mentioned in the Guidelines. On the one hand, it was revealed that the stakeholder groups worker and value chain actors were underrepresented in the reviewed literature, and on the other hand, many indicators could be directly used from the Guidelines and the PSIA handbook. Furthermore, the indicators that were found in the reviewed literature present a huge variety and diversity, and this makes it difficult to define a consistent assessment method. However, based on the reviewed literature and supplemented by missing aspects from the 
Table 7 Reference scale and performance reference points for all quantitative indicators

\begin{tabular}{|c|c|c|c|c|c|c|c|}
\hline \multirow[t]{2}{*}{ Category } & \multirow[t]{2}{*}{ Indicator } & \multirow[t]{2}{*}{ Unit } & \multicolumn{5}{|c|}{ Reference scale and performance reference points ${ }^{\mathrm{a}}$} \\
\hline & & & -2 & -1 & 0 & 1 & 2 \\
\hline \multicolumn{8}{|l|}{ Local community } \\
\hline Public space & Green and open space per capita & $\frac{\left(\mathrm{m}^{2}\right)}{\text { Inhabitants }}$ & $0-5$ & $5-10$ & $10-25$ & $25-50$ & $>50$ \\
\hline \multirow[t]{4}{*}{ Air quality } & Emission intensity of $\mathrm{NO}_{x}$ & $\frac{\mathrm{NO}_{x}(\mathrm{mg})}{\mathrm{Pkm}}$ & $>1000$ & $475-1000$ & $50-475$ & $1-50$ & $0-1$ \\
\hline & Emission intensity of $\mathrm{PM}_{10}$ & $\frac{\mathrm{PM}_{10}(\mathrm{mg})}{\mathrm{Pkm}}$ & $>20$ & $15-20$ & $10-15$ & $5-10$ & $0-5$ \\
\hline & Emission intensity of $\mathrm{PM}_{2,5}$ & $\frac{\mathrm{PM}_{2.5}(\mathrm{mg})}{\mathrm{Pkm}}$ & $>20$ & $15-20$ & $10-15$ & $5-10$ & $0-5$ \\
\hline & Emission intensity of $\mathrm{SO}_{2}$ & $\frac{\mathrm{SO}_{2}(\mathrm{mg})}{\mathrm{Pkm}}$ & $>1$ & $0.75-1$ & $0.5-0.75$ & $0.25-0.5$ & $0-0.25$ \\
\hline \multirow[t]{2}{*}{ Employment } & Percentage of employees hired & Ratio & $>-10$ & -10 to -5 & -5 to +5 & $5-10$ & $<10$ \\
\hline & Percentage of employees hired locally & Ratio & $0-20$ & $20-40$ & $40-60$ & $60-80$ & $80-100$ \\
\hline \multirow[t]{2}{*}{ Noise pollution } & Noise pollution greater than $65 \mathrm{~dB}$ & Ratio & $>20$ & $10-20$ & $1-10$ & $0.1-1$ & 0 \\
\hline & Average emissions of noise & Ratio & $>20$ & $10-20$ & $1-10$ & $0.1-1$ & 0 \\
\hline \multirow[t]{3}{*}{ Space occupancy } & Infrastructure efficiency & $\frac{\left(\mathrm{m}^{2}\right)}{\mathrm{Pkm}} *$ & $>1$ & $0.75-1$ & $0.5-0.75$ & $0.25-0.5$ & $0-0.25$ \\
\hline & Infrastructure space occupancy & Ratio & $>50$ & $10-50$ & $1-10$ & $0.1-1$ & $0-0.1$ \\
\hline & $\begin{array}{l}\text { Space occupancy in relation to green } \\
\text { and open space }\end{array}$ & Ratio & $>50$ & $10-50$ & $1-10$ & $0.1-1$ & $0-0.1$ \\
\hline \multicolumn{8}{|l|}{ Consumers } \\
\hline \multirow[t]{2}{*}{ Accessibility } & Number of transport points & Ratio & $<50$ & $50-100$ & $100-500$ & $500-1000$ & $>1000$ \\
\hline & Number of passengers & count (in millions) & $<10$ & $10-100$ & $100-250$ & $250-500$ & $>500$ \\
\hline Safety & Fatal and non-fatal traffic accidents & Ratio ** & $>2.0$ & $1.0-2.0$ & $0.5-1.0$ & $0.1-0.5$ & $0-0.1$ \\
\hline Convenience & Punctuality of deliveries & Ratio & $<80$ & $80-90$ & $90-95$ & 95-99 & 100 \\
\hline Affordability & Trip fare & $€$ & $>4.5$ & $3.5-4.5$ & $2.5-3.5$ & $1.5-2.5$ & $0-1.5$ \\
\hline Feedback mechanism & Consumer complaints & Ratio * & $>0.04$ & $0.03-0.04$ & $0.02-0.03$ & $0.01-0.02$ & $0-0.01$ \\
\hline \multicolumn{8}{|l|}{ Worker } \\
\hline Safety & Fatal and non-fatal injuries & Ratio $* * *$ & $>60$ & $45-60$ & $30-45$ & $15-30$ & $0-15$ \\
\hline Fair salary & Minimum wage paid & Ratio & $<80$ & $80-90$ & $90-95$ & $95-99$ & 100 \\
\hline \multicolumn{8}{|l|}{ Value chain actors } \\
\hline Promoting social responsibility & Percentage of audited suppliers & Ratio & $0-20$ & $20-40$ & $40-60$ & $60-80$ & $80-100$ \\
\hline \multicolumn{8}{|c|}{ Society } \\
\hline \multirow[t]{3}{*}{ Health } & $\mathrm{GWP}_{100}\left(\mathrm{CO}_{2}\right.$ equiv. $)$ & $\frac{\mathrm{CO}_{2} \text { equiv. (g) }}{\text { Pkm }}$ & $>160$ & $120-160$ & $80-120$ & $40-80$ & $0-40$ \\
\hline & Acidification potential ( $\mathrm{SO}_{2}$ equiv.) & $\frac{\mathrm{SO}_{2} \text { equiv. (mg) }}{\text { Pkm }}$ & $>400$ & $300-400$ & $200-300$ & $100-200$ & $0-100$ \\
\hline & Eutrophication potential ( $\mathrm{PO}_{4}$ equiv.) & $\frac{\mathrm{PO}_{4} \text { equiv. }(\mathrm{mg})}{\mathrm{Pkm}}$ & $>100$ & $75-100$ & $50-75$ & $25-50$ & $0-25$ \\
\hline Tax income & Taxes per pkm & $€$ & $0-0.02$ & $0.02-0.04$ & $0.04-0.06$ & $0.06-0.08$ & $>0.08$ \\
\hline
\end{tabular}

${ }^{a}$ Performance reference points are defined based on possible $\min /$ max values

*Indicator values $\times 1000$ for reference scale

**Per million passenger kilometre

***Per 1000 employees

Guidelines and the PSIA, a holistic set of 39 indicators for the assessment of mobility services is proposed, including an assessment method for every indicator. Out of the total set of indicators, 25 are of quantitative and 14 of qualitative nature. For the stakeholder group local community, 13 indicators are proposed, out of which only one is a qualitative indicator. Out of the eight indicators suggested for the stakeholder group consumers, two are qualitative. However, the stakeholder group workers also comprises eight indicators from which six are qualitative. For the stakeholder group value chain actors, five indicators are proposed, with four qualitative indicators and one quantitative indicator. Contrary, for the stakeholder group society, five indicators are proposed in total, out of which only one is qualitative.

It is the first time that indicators from previous studies in the field of urban mobility were systematically analysed, evaluated and allocated to stakeholder groups in order to find suitable indicators for social sustainability of mobility services. Thus, this systematic approach as well as the resulting insights constitute not only a novelty 
Table 8 Defined reference scale and performance indicators for all qualitative indicators that are not part of the PSIA

Value Chain Actors

Fair Competition

2 The company or facility has a system in place to enforce fair 1-3 AND 5-6 competition, which the employees are regularly trained on. Suppliers also need to behave in a competitive way.

1 The company or facility has a system in place to enforce fair 1-3 AND 5 competition, which the employees are regularly trained on.

0 The company or facility has a system in place to enforce the policy that prohibits anti-competitive behavior and violations of anti-trust and monopoly legislation

AND

There is evidence that there is no violation of fair competition.

-1 Incidents of anti-competitive behavior or violation of anti-trust and monopoly legislation were discovered and a corrective action plan with a clear timeline for completion has been developed

OR

The company or facility has a policy that prohibits anti-competitive behavior, but does not have a system in place to enforce it.

-2 Anti-competitive behavior or violations of anti-trust and monopoly legislation have been discovered within the company or facility, however, a corrective action plan with a clear timeline for completion has not been developed.

1. The company or facility has a policy that prohibits anti-competitive behavior and violations of anti-trust and monopoly legislation.

2. The company or facility has a system in place to enforce the policy that prohibits anti-competitive behavior and violations of anti-trust and monopoly legislation.

3. There is no evidence that the company or facility has acted in an anti-competitive way and no violations of anti-trust or monopoly legislation are registered.

4. If incidents have been discovered that the company or facility is/has been in violation of anti-trust and monopoly legislation, the company has developed a corrective action plan with a clear timeline for completion.

5. Employees are trained regularly on the importance of compliance and fair competition.

6. Suppliers are only chosen by the company or facility if they also act in a competitive way without violation of anti-trust and monopoly legislation and suppliers are requested to foster fair competition themselves.

Supplier Relationships

2 The company or facility has a system in place to not only

1 The company or facility has a system in place to not only

0 The company or facility has a system in place to enforce the

1-3 AND 5-6

AND

There is evidence that there is no misuse of power over

-1 Incidents of misusing the power over suppliers have been timeline for completion has been developed OR
Intellectual Property Rights

2 The company or facility has a PDCA process in place to raise awareness of intellectual property rights and compliant behavior. The commitments, performance, progress and effectiveness of programs are reported publicly.

1 The company or facility has a PDCA process in place to 1-3 raise awareness of intellectual property rights and compliant behavior.

0 The company or facility has a system in place to enforce the 1-3 policy safeguarding and valuing intellectual property rights

AND

No incidents have been discovered that the company or facility has been neglecting intellectual property rights.

-1 Incidents of misuse of intellectual property rights have been 1 OR 4 discovered within the company or facility and a corrective action plan with a clear timeline for completion has been developed

OR

The company or facility has a policy safeguarding intellectual property rights but does not have a system in place to enforce it.

-2 Incidents of misuse of intellectual property rights have been discovered within the company or facility, however, a corrective action plan with a clear timeline for completion has not been developed.

1. The company or facility has a policy that safeguards and values intellectual property rights.

2. The company or facility has a system in place to enforce the policy that safeguards and values intellectual property rights (patents, copyrights and trademarks).

3. There is no evidence that the company or facility has neglected intellectual property rights.

4. If incidents have been discovered that the company or facility is/has been neglecting intellectual property rights, the company has developed a corrective action plan with a clear timeline for completion.

5. The company or facility has a PDCA process in place to raise awareness of intellectual property rights and compliant behavior.

6. Company commitments and progress on PDCA model are reported publicly.

Promoting Social Responsibility

2 The company or facility has a system in place to not only enforce the policy safeguarding fair trading conditions but to actively raise awareness for it. The commitments and progress of programmes are reported publicly. enforce the policy safeguarding fair trading conditions but to actively raise awareness for it. policy safeguarding fair trading conditions suppliers. discovered and a corrective action plan with a clear enforce but actively raise awareness for social responsibility. Suppliers also need to demand for social responsibility in their supply chain.

1 The company or facility has a system in place to not only enforce but actively raise awareness for social responsibility.

0 The company or facility has a system to enforce the principles of the code of conduct that protects human rights of workers among suppliers

AND

Contracts with suppliers include defined standards regarding ethical, social, environmental and gender equality criterions.

1 OR $4-1$ The company or facility has a code of conduct that protects human rights of workers among suppliers, but does not have a system to enforce the code of conduct. R 
Table 8 (continued)

Value Chain Actors

The company or facility has a policy safeguarding fair trading conditions but does not have a system in place to enforce it.

-2 Incidents of misusing the power over suppliers have been discovered, however, a corrective action plan with a clear timeline for completion has not been developed.

1. The company or facility has a policy that safeguards fair trading conditions, including sufficient lead time, reasonable volume fluctuations and on time payments to suppliers.

2. The company or facility has a system in place to enforce the policy that safeguards fair trading conditions.

3. There is no evidence that the company or facility has misused their power over sup-pliers and no incidents regarding unfair trading conditions were reported.

4. If incidents have been discovered that the company or facility is/has been misusing their power over suppliers, the company has developed a corrective action plan with a clear timeline for completion.

5. The company or facility is actively raising awareness for fair trading conditions (e.g. by trainings for employees).

6. Company commitments and progress regarding fair trading conditions are reported publicly.

Society

Urban development

2 The company or facility is a member in a joint initiative of city authorities and mobility service providers to jointly develop sustainable urban mobility concepts and its mobility solutions contribute to city's development plans.

1 The company or facility has a system in place to ensure that decisions regarding mobility solutions are in line with city development plans

\section{AND}

The company or facility is in regular exchange with city authorities to positively contribute to city development.

0 The company or facility has a system in place to ensure that decisions regarding mobility solutions are in line with city development plan.

-1 The company or facility is only in exchange with city authorities to inform about their plans or clarify legal frameworks.

-2 The company or facility is not in exchange with city authorities to inform about their plans or contribute to city development.

1. The company or facility has a system in place to ensure that decisions regarding mobility solutions are agreed by city authorities and decisions are in line with city development plans.

2. The company or facility is regularly in exchange with city authorities to positively contribute to city development.

3. The company or facility is a member in a joint initiative of city authorities and mobility service providers to develop sustainable urban mobility concepts together with city representatives.

4. The company or facility is only in exchange with city authorities to inform about their plans or clarify legal frameworks.

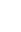

-2 There is no code of conduct that protects human rights of workers among suppliers.

1. The company or facility has a code of conduct that protects human rights of workers among suppliers.

2. The company or facility has a system in place to enforce the principles of the code of conduct that protects human rights of workers among suppliers.

3. The company or facility is a member in an initiative that promotes social responsibility along the supply chain.

4. In a purchasing policy or contracts with suppliers, criteria regarding ethical, social, environmental and gender equality standards are defined and must be fulfilled.

5. The company or facility is actively raising awareness for social responsibility issues (e.g. by trainings for suppliers).

6. The suppliers of the company or facility themselves are requested to demand for so-cial responsibility in their supply chain. but also a major strength of this study. For the literature review, three major databases were selected and search terms were defined in order to find suitable publications with relevant social indicators. The selected search terms needed to be both general enough to find social indicators and specific enough to find social indicators that meet the particular needs of mobility services. To overcome this challenge, general search terms like 'Social LCA' were combined with specific search terms like 'Mobility Services' or 'Transportation Systems'. The selection of search terms influences the results, which is why the selected databases as well as the defined search terms can be seen as a limitation of this study. Additional keyword combinations in more databases could improve the results. 
To validate the applicability of the suggested indicators and the proposed assessment method, further research and implementation to real case studies are necessary. The obvious next step is therefore the application of the proposed set of indicators to mobility service case studies. This application and the subsequent evaluation are regarded as essential for the validation. In a further step, the results of the social impact assessment can be combined with an environmental impact assessment, for a holistic approach. Special attention should be paid to social indicators that might already be included in the environmental dimension, for example indicators assessing air quality. These indicators should only be included once, either in the social or in the environmental dimension, to avoid double counting. The combined assessment of social and environmental impacts of mobility services is considered as an important part of future research objectives. In addition, further research concerning the development of impact pathways helps to better understand the implications of mobility services and can help to facilitate the application of indicators. In that way, the proposed set of indicators may help to answer the frequently asked question whether mobility services can improve quality of life in cities.

Funding Information Open Access funding provided by Projekt DEAL.

Open Access This article is licensed under a Creative Commons Attribution 4.0 International License, which permits use, sharing, adaptation, distribution and reproduction in any medium or format, as long as you give appropriate credit to the original author(s) and the source, provide a link to the Creative Commons licence, and indicate if changes were made. The images or other third party material in this article are included in the article's Creative Commons licence, unless indicated otherwise in a credit line to the material. If material is not included in the article's Creative Commons licence and your intended use is not permitted by statutory regulation or exceeds the permitted use, you will need to obtain permission directly from the copyright holder. To view a copy of this licence, visit http://creativecommons.org/licenses/by/4.0/.

\section{References}

Ameen RFM, Mourshed M (2019) Urban sustainability assessment framework development: the ranking and weighting of sustainability indicators using analytic hierarchy process. Sustain Cities Soc 44: 356-366. https://doi.org/10.1016/j.scs.2018.10.020

Anisurrahman M, Alshuwaikhat HM (2019) Determining sustainability assessment indicators for the Holy City of Makkah, Saudi Arabia. Arab J Sci Eng 44:5165-5178. https://doi.org/10.1007/s13369-019-03772-3

Aparcana S, Salhofer S (2013) Development of a social impact assessment methodology for recycling systems in low-income countries. Int J Life Cycle Assess 18:1106-1115. https://doi.org/10.1007/ s11367-013-0546-8

Azami M, Mirzaee E, Mohammadi A (2015) Recognition of urban unsustainability in Iran (case study: Sanandaj City). Cities 49:159168. https://doi.org/10.1016/j.cities.2015.08.005

Bandeira RAM, D'Agosto MA, Ribeiro SK et al (2018) A fuzzy multicriteria model for evaluating sustainable urban freight transportation operations. J Clean Prod 184:727-739. https://doi.org/10.1016/j. jclepro.2018.02.234
Blomberg SNF, Rosenkrantz CO, Lippert F (2019) Injury from electric scooters in Copenhagen: a retrospective cohort study. BMJ Open 9: 1-8. https://doi.org/10.1136/bmjopen-2019-033988

Bui NT, Kawamura A, Kim KW, Prathumratana L, Kim TH, Yoon SH, Jang M, Amaguchi H, Bui DD, Truong NT (2017) Proposal of an indicator-based sustainability assessment framework for the mining sector of APEC economies. Res Policy 52:405-417. https://doi.org/ 10.1016/j.resourpol.2017.05.005

Burrows A, Bradburn J, Cohen DT (2015) Journeys of the future. Introducing mobility as a service

Chang YJ, Sproesser G, Neugebauer S, Wolf K, Scheumann R, Pittner A, Rethmeier M, Finkbeiner M (2015) Environmental and social life cycle assessment of welding technologies. Procedia CIRP 26:293298. https://doi.org/10.1016/j.procir.2014.07.084

Chhipi-Shrestha GK, Hewage K, Sadiq R (2014) 'Socializing' sustainability: a critical review on current development status of social life cycle impact assessment method. Clean Techn Environ Policy 17: 579-596. https://doi.org/10.1007/s10098-014-0841-5

Choon SW, Siwar C, Pereira JJ, Jemain AA, Hashim HS, Hadi AS (2011) A sustainable city index for Malaysia. Int J Sustain Dev World Ecol 18:28-35. https://doi.org/10.1080/13504509.2011.543012

Curran MA (1996) Environmental life-cycle assessment. Int J Life Cycle Assess 1:179-179

de Oliveira Cavalcanti C, Limont M, Dziedzic M, Fernandes V (2017) Sustainability of urban mobility projects in the Curitiba metropolitan region. Land Use Policy 60:395-402. https://doi.org/10.1016/j. landusepol.2016.11.015

Di Cesare S, Silveri F, Sala S (2018) Positive impacts in social life cycle assessment: state of the art and the way forward:406-421. https:// doi.org/10.1007/s11367-016-1169-7

Ding X, Zhong W, Shearmur RG, Zhang X, Huisingh D (2015) An inclusive model for assessing the sustainability of cities in developing countries - trinity of cities' sustainability from spatial, logical and time dimensions (TCS-SLTD). J Clean Prod 109:62-75. https:// doi.org/10.1016/j.jclepro.2015.06.140

Dizdaroglu D, Yigitcanlar T (2014) A parcel-scale assessment tool to measure sustainability through urban ecosystem components: the MUSIX model. Ecol Indic 41:115-130. https://doi.org/10.1016/j. ecolind.2014.01.037

Dubois-Iorgulescu A-M, Saraiva AKE, Valle R, Rodrigues LM (2016) How to define the system in social life cycle assessments ? A critical review of the state of the art and identification of needed developments. Int J Life Cycle Assess 23:507-518. https://doi.org/10.1007/ s11367-016-1181-y

Dur F, Yigitcanlar T, Bunker J (2014) A spatial-indexing model for measuring neighbourhood-level land-use and transport integration. Environ Plan B Plan Des 41:792-812. https://doi.org/10.1068/b39028

Durand A, Harms L, Hoogendoorn-lanser S, Zijlstra T (2018) Mobilityas-a-service and changes in travel preferences and travel behaviour: a literature review. KiM Netherlands Inst Transp Policy

Ekener-Petersen E, Höglund J, Finnveden G (2014) Screening potential social impacts of fossil fuels and biofuels for vehicles. Energy Policy 73:416-426. https://doi.org/10.1016/j.enpol.2014.05.034

Feleki E, Vlachokostas C, Moussiopoulos N (2018) Characterisation of sustainability in urban areas: an analysis of assessment tools with emphasis on European cities. Sustain Cities Soc 43:563-577. https:// doi.org/10.1016/j.scs.2018.08.025

Finkbeiner M, Schau EM, Lehmann A, Traverso M (2010) Towards life cycle sustainability assessment. Sustain 2:3309-3322. https://doi. org $/ 10.3390 /$ su2103309

Fontes J, Carmen A, Saling P, et al (2016) Handbook for product social impact assessment. https://www.researchgate.net/publication/ 312802992_Handbook_for_Product_Social_Impact_Assessment 30. Accessed 30 Dec 2019

Fouda YES, Elkhazendar DM (2019) A criterion for modelling the 'liveand-work' city index using sustainable development indicators. Int J 
Urban Sustain Dev 11:24-47. https://doi.org/10.1080/19463138. 2018.1556161

Franze J, Ciroth A (2011) A comparison of cut roses from Ecuador and the Netherlands. Int J Life Cycle Assess 16:366-379. https://doi.org/ 10.1007/s11367-011-0266-x

Goedkoop MJ, Indrane D, de Beer IM (2018) Handbook for product social impact assessment. https://product-social-impact-assessment. com/. Accessed 30 Dec 2019

Gonzalez-Garcia S, Manteiga R, Moreira MT, Feijoo G (2018) Assessing the sustainability of Spanish cities considering environmental and socio-economic indicators. J Clean Prod 178:599-610. https://doi. org/10.1016/j.jclepro.2018.01.056

Gould E, Wehrmeyer W, Leach M, Electric S (2015) Transition pathways of e-mobility services. Trans Ecol Environ 194:349-359. https://doi. org/10.2495/SC150311

Gross M (2019) The future is urbanised. Curr Biol 29:R947-R949. https://doi.org/10.1016/j.cub.2019.09.043

Haghshenas H, Vaziri M (2012) Urban sustainable transportation indicators for global comparison. Ecol Indic 15:115-121. https://doi.org/ 10.1016/j.ecolind.2011.09.010

Harijani AM, Mansour S, Karimi B (2017) A multi-objective model for sustainable recycling of municipal solid waste. Waste Manag Res 35:387-399. https://doi.org/10.1177/0734242X17693685

Hély V, Antoni JP (2019) Combining indicators for decision making in planning issues: a theoretical approach to perform sustainability assessment. Sustain Cities Soc 44:844-854. https://doi.org/10.1016/j. scs.2018.10.035

Hietanen S (2014) Mobility as a service - the new transport model? ITS $\&$ transport management supplement. Eurotransport 12:2-4

Huovila A, Bosch P, Airaksinen M (2019) Comparative analysis of standardized indicators for smart sustainable cities: what indicators and standards to use and when? Cities 89:141-153. https://doi.org/10. 1016/j.cities.2019.01.029

ISO 14040 (2006) Environmental management - life cycle assessment principles and framework

Jasti PC, Ram V (2018) Integrated performance assessment and service level benchmarking of urban bus system using fuzzy logic. Eur Transp

Jittrapirom P, Caiati V, Feneri A-M et al (2017) Mobility as a service: a critical review of definitions, assessments of schemes and key challenges. Urban Plan 2:13-25. https://doi.org/10.17645/up.v2i2.931

Kamargianni M, Li W, Matyas M, Schäfer A (2016) A critical review of new mobility services for urban transport. Transp Res Proc 14: 3294-3303. https://doi.org/10.1016/j.trpro.2016.05.277

Karlsson ICM, Mukhtar-Landgren D, Smith G, Koglin T, Kronsell A, Lund E, Sarasini S, Sochor J (2019) Development and implementation of mobility-as-a-service - a qualitative study of barriers and enabling factors. Transp Res A Policy Pract 131:283-295. https:// doi.org/10.1016/j.tra.2019.09.028

Kawakubo S, Murakami S, Ikaga T, Asami Y (2018) Sustainability assessment of cities: SDGs and GHG emissions. Build Res Inf 46: 528-539. https://doi.org/10.1080/09613218.2017.1356120

Kunstler M, Philibert-Petit E, Steil L (2016) The future of cities measuring sustainability. https://assets.kpmg/content/dam/kpmg/nz/pdf/ March/the-future-of-cities-measuring-sustainability.pdf. Accessed 30 Apr 2020

Laprise M, Lufkin S, Rey E (2015) An indicator system for the assessment of sustainability integrated into the project dynamics of regeneration of disused urban areas. Build Environ 86:29-38. https://doi. org/10.1016/j.buildenv.2014.12.002

Laprise M, Lufkin S, Rey E (2018) An operational monitoring tool facilitating the transformation of urban brownfields into sustainable neighborhoods. Build Environ 142:221-233. https://doi.org/10. 1016/j.buildenv.2018.06.005

Li C, Li J (2017) Assessing urban sustainability using a multi-scale, theme-based indicator framework: a case study of the Yangtze
River Delta region, China. Sustain 9:7-9. https://doi.org/10.3390/ su9112072

Litman T, Burwell D (2006) Issues in sustainable transportation. Int J Glob Environ Issues 6:331-337

Lu C, Xue B, Lu C, Wang T, Jiang L, Zhang Z, Ren W (2016) Sustainability investigation of resource-based cities in northeastern China. Sustain 8:1-16. https://doi.org/10.3390/su8101058

Lu Y, Geng Y, Liu Z, Cote R, Yu X (2017) Measuring sustainability at the community level: an overview of China's indicator system on National Demonstration Sustainable Communities. J Clean Prod 143:326-335. https://doi.org/10.1016/j.jclepro.2016.12.105

Mansourianfar MH, Haghshenas H (2018) Micro-scale sustainability assessment of infrastructure projects on urban transportation systems: case study of Azadi district, Isfahan, Iran. Cities 72:149-159. https:// doi.org/10.1016/j.cities.2017.08.012

Mapar M, Jafari MJ, Mansouri N, Arjmandi R, Azizinejad R, Ramos TB (2017) Sustainability indicators for municipalities of megacities: integrating health, safety and environmental performance. Ecol Indic 83:271-291. https://doi.org/10.1016/j.ecolind.2017.08.012

Miller P, de Barros AG, Kattan L, Wirasinghe SC (2016) Analyzing the sustainability performance of public transit. Transp Res D Transp Environ 44:177-198. https://doi.org/10.1016/j.trd.2016.02.012

Moon-Miklaucic C, Bray-Sharpin A, Lanza I, et al (2019) The evolution of bike sharing: 10 questions on the emergence of new technologies, opportunities, and risks

Morrison PS, Beer B (2017) Consumption and environmental awareness: demographics of the European experience. In: Socioeconomic environmental policies and evaluations in regional science. Springer, Singapore, pp 81-102

Onat NC, Kucukvar M, Tatari O (2014) Towards life cycle sustainability assessment of alternative passenger vehicles

Opher T, Shapira A, Friedler E (2018) A comparative social life cycle assessment of urban domestic water reuse alternatives. Int J Life Cycle Assess 23:1315-1330. https://doi.org/10.1007/s11367-017-1356-1

Oregi X, Pousse M, Mabe L, Escudero A, Mardaras I (2016) Sustainability assessment of three districts in the city of donostia through the NEST simulation tool. Nat Resour Forum 40:156168. https://doi.org/10.1111/1477-8947.12104

Oses U, Rojí E, Gurrutxaga I, Larrauri M (2017) A multidisciplinary sustainability index to assess transport in urban areas: a case study of Donostia-San Sebastian, Spain. J Environ Plan Manag 60:18911922. https://doi.org/10.1080/09640568.2016.1264374

Oswald Beiler M, Mohammed M (2016) Exploring transportation equity: development and application of a transportation justice framework. Transp Res D Transp Environ 47:285-298. https://doi.org/10.1016/ j.trd.2016.06.007

Papoutsis K, Dewulf W, Vanelslander T, Nathanail E (2018) Sustainability assessment of retail logistics solutions using external costs analysis: a case-study for the city of Antwerp. Eur Transp Res Rev 10. https://doi.org/10.1186/s12544-018-0297-5

Parent J, Cucuzzella C, Revéret J (2010) Impact assessment in SLCA: sorting the sLCIA methods according to their outcomes. Int J Life Cycle Assess:164-171. https://doi.org/10.1007/s11367-009-0146-9

Petti L, Serreli M, Di Cesare S (2016) Systematic literature review in social life cycle assessment. Int J Life Cycle Assess 23:422-431. https://doi.org/10.1007/s11367-016-1135-4

Pham TT, Kuo T, Tseng M, et al (2019) Industry 4.0 to accelerate the circular economy: a case study of electric scooter sharing. 1-16

Philipps S (2019) Carsharing market \& growth analysis 2019

Phillis YA, Kouikoglou VS, Verdugo C (2017) Urban sustainability assessment and ranking of cities. Comput Environ Urban Syst 64: 254-265. https://doi.org/10.1016/j.compenvurbsys.2017.03.002

Rajak S, Parthiban P, Dhanalakshmi R (2016) Sustainable transportation systems performance evaluation using fuzzy logic. Ecol Indic 71: 503-513. https://doi.org/10.1016/j.ecolind.2016.07.031 
Rajaonson J, Tanguay GA (2017) A sensitivity analysis to methodological variation in indicator-based urban sustainability assessment: a Quebec case study. Ecol Indic 83:122-131. https://doi.org/10.1016/ j.ecolind.2017.07.050

Ramirez KPS, Petti L, Haberland NT, Ugaya CML (2014) Subcategory assessment method for social life cycle assessment. Part 1: methodological framework. Int J Life Cycle Assess. https://doi.org/10. 1007/s11367-014-0761-y

Reisi M, Aye L, Rajabifard A, Ngo T (2014) Transport sustainability index: Melbourne case study. Ecol Indic 43:288-296. https://doi. org/10.1016/j.ecolind.2014.03.004

Reuter B (2016) Assessment of sustainability issues for the selection of materials and technologies during product design: a case study of lithium-ion batteries for electric vehicles. Int J Interact Des Manuf 10:217-227. https://doi.org/10.1007/s12008-016-0329-0

Robati M, Monavari SM, Majedi H (2015) Urban environment quality assessment by using composite index model. Environ Prog Sustain Energy 35:809-814. https://doi.org/10.1002/ep.12125

Russo Garrido S, Parent J, Beaulieu L, Revéret J (2016) A literature review of type I SLCA - making the logic underlying methodological choices explicit. Int J Life Cycle Assess 23:432-444. https://doi. org/10.1007/s11367-016-1067-z

Saleem M, Chhipi-Shrestha G, Túlio Barbosa Andrade M, Dyck R, Ruparathna R, Hewage K, Sadiq R (2018) Life cycle thinkingbased selection of building facades. J Archit Eng 24. https://doi. org/10.1061/(ASCE)AE.1943-5568.0000333

Science for Environment Policy (2018) Indicators for sustainable cities. In-depth Report 12

SETAC Workshop Report (1993) A conceptual framework for life-cycle impact assessment

Shaheen S, Cohen A, Chan N, Bansal A (2020) Sharing strategies: carsharing, shared micromobility (bikesharing and scooter sharing), transportation network companies, microtransit, and other innovative mobility modes. Elsevier Inc.

Shi L, Vause J, Gao L, Li Q, Tang L (2011) Temporal changes in sustainable development level for Lijiang City: 2003-2008. Int J Sustain Dev World Ecol 18:474-479. https://doi.org/10.1080/ 13504509.2011.601470

Shmelev SE, Shmeleva IA (2018) Global urban sustainability assessment: a multidimensional approach. Sustain Dev 26:904-920. https://doi.org/10.1002/sd.1887

Spulber A, Dennis EP, Wallace R, Schultz M (2016) The impact of new mobility services on the automotive industry

Stender M, Walter A (2018) The role of social sustainability in building assessment. Build Res Inf 47:598-610. https://doi.org/10.1080/ 09613218.2018.1468057

Tan Y, Jiao L, Shuai C, Shen L (2018) A system dynamics model for simulating urban sustainability performance: a China case study. J Clean Prod 199:1107-1115. https://doi.org/10.1016/j.jclepro.2018. 07.154

Tarne P, Traverso M, Finkbeiner M (2017) Review of life cycle sustainability assessment and potential for its adoption at an automotive company. Sustain 9. https://doi.org/10.3390/su9040670
UNEP/SETAC (2009) Guidelines for social life cycle assessment of products. http://wedocs.unep.org/handle/20.500.11822/7912. Accessed 30 Dec 2019

UNEP/SETAC (2013) The methodological sheets for sub-categories in social life cycle assessment (S-LCA). https://www. lifecycleinitiative.org/wp-content/uploads/2013/11/S-LCA_ methodological_sheets_11.11.13.pdf. Accessed 30 Dec 2019

United Nations (201) World urbanization prospects. The 2011 revision

Ustaoglu E, Williams B, Petrov LO (2017) Scenario analysis of alternative land development patterns for the Leipzig-Halle region: implications for transport-land-use sustainability. Urban Plan 2:108-129. https://doi.org/10.17645/up.v2i1.838

Verseckiene A, Palsaitis R, Yatskiv I (2017) Evaluation of alternatives to integrate special transportation services for people with movement disorders. Transp Telecommun 18:263-274. https://doi.org/10. 1515/ttj-2017-0023

WBCSD (2015) Methodology and indicator calculation method for sustainable urban mobility. http://docs.wbcsd.org/2015/12/SMP2.0 Sustainable-Mobility-Indicators_ENG.pdf. Accessed 10 Jan 2020

Weidema BP (2018) The social footprint - a practical approach to comprehensive and consistent social LCA. Int J Life Cycle Assess 23: 700-709. https://doi.org/10.1007/s11367-016-1172-z

Wey WM, Huang JY (2018) Urban sustainable transportation planning strategies for livable city's quality of life. Habitat Int 82:9-27. https://doi.org/10.1016/j.habitatint.2018.10.002

Wu S, Li D, Wang X, Li S (2018) Examining component-based city health by implementing a fuzzy evaluation approach. Ecol Indic 93:791-803. https://doi.org/10.1016/j.ecolind.2018.05.082

Xu Z, Coors V (2012) Combining system dynamics model, GIS and 3D visualization in sustainability assessment of urban residential development. Build Environ 47:272-287. https://doi.org/10.1016/j. buildenv.2011.07.012

Yi P, Li W, Zhang D (2019) Assessment of city sustainability using MCDM with interdependent criteria weight. Sustain 11:1-20. https://doi.org/10.3390/su11061632

Yigitcanlar T, Dur F, Dizdaroglu D (2015) Towards prosperous sustainable cities: a multiscalar urban sustainability assessment approach. Habitat Int 45:36-46. https://doi.org/10.1016/j.habitatint.2014.06.033

Zanchi L, Delogu M, Zamagni A, Pierini M (2018) Analysis of the main elements affecting social LCA applications: challenges for the automotive sector. Int J Life Cycle Assess 23:519-535. https://doi.org/ 10.1007/s11367-016-1176-8

Zheng HW, Shen GQP, Song Y, Sun B, Hong J (2017) Neighborhood sustainability in urban renewal: an assessment framework. Environ Plan B Urban Anal City Sci 44:903-924. https://doi.org/10.1177/ 0265813516655547

Zope R, Vasudevan N, Arkatkar SS, Joshi G (2019) Benchmarking: a tool for evaluation and monitoring sustainability of urban transport system in metropolitan cities of India. Sustain Cities Soc 45:48-58. https://doi.org/10.1016/j.scs.2018.11.011

Publisher's note Springer Nature remains neutral with regard to jurisdictional claims in published maps and institutional affiliations. 